\title{
The Role of pH in PEG-b-PAAc Modification of Gadolinium Oxide Nanostructures for Biomedical Applications
}

\author{
Eva Hemmer, ${ }^{1,2}$ Nallusamy Venkatachalam, ${ }^{2}$ Hiroshi Hyodo, ${ }^{2}$ and Kohei Soga ${ }^{1,2}$ \\ ${ }^{1}$ Center for Technologies against Cancer (CTC), Tokyo University of Science, 2669 Yamazaki Noda, Chiba 278-0022, Japan \\ ${ }^{2}$ Department of Materials Science and Technology, Tokyo University of Science, 2641 Yamazaki Noda, Chiba 278-8510, Japan
}

Correspondence should be addressed to Eva Hemmer, eva.hemmer@sogalabo.jp

Received 6 February 2012; Accepted 26 June 2012

Academic Editor: Dachamir Hotza

Copyright (C) 2012 Eva Hemmer et al. This is an open access article distributed under the Creative Commons Attribution License, which permits unrestricted use, distribution, and reproduction in any medium, provided the original work is properly cited.

\begin{abstract}
Upconversion and near-infrared emitting $\mathrm{Gd}_{2} \mathrm{O}_{3}: \mathrm{Er}^{3+}, \mathrm{Yb}^{3+}$ nanostructured phosphors (nanoparticles and nanorods) for applications in bioimaging have been synthesized by precipitation methods and hydrothermal treatment. Variation of the material synthesis conditions (additives and $\mathrm{pH}$ ) allows controlling particle size ( $40 \mathrm{~nm}$ to $\mu \mathrm{m}$ range) and rod aspect ratio (5 to 18). It was shown that PEG- $b$-PAAc (poly(ethylene glycol) poly(acrylic acid) block polymer) is suitable to provide the required chemical durability, dispersion stability, and noncytotoxic behaviour for biomedical applications, where the coating of $\mathrm{Gd}_{2} \mathrm{O}_{3}$ with a protecting and biocompatible layer is essential in order to prevent the release of toxic $\mathrm{Gd}^{3+}$ ions. Physicochemical properties of the $\mathrm{Gd}_{2} \mathrm{O}_{3}: \mathrm{Er}^{3+}, \mathrm{Yb}^{3+}$ nanostructures modified with PEG- $b$-PAAc have been investigated by TG-DTA, FT-IR, and DLS revealing a strong influence of modification conditions, namely, $\mathrm{pH}$ of the reaction media, on the nature of the PEG- $b$-PAAc layer.
\end{abstract}

\section{Introduction}

Optical imaging techniques for biomedical applications on the basis of fluorescent probes are recently attracting increasing attention. However, drawbacks of commonly used dyes and markers are the poor photostability in case of organic dyes, toxicity of quantum dots and, most severe, autofluorescence from the biological tissue, high absorption by haemoglobin as well as light scattering when ultraviolet (UV) or visible (VIS) light is used as excitation source [1]. Upconverting phosphors, like lanthanide (Ln) containing inorganic compounds emitting light in the visible and near-infrared (NIR) range when excited with NIR light, are interesting candidates to overcome those problems. Rare-earth oxides like yttrium oxide doped with erbium and ytterbium ions, $\mathrm{Y}_{2} \mathrm{O}_{3}: \mathrm{Er}^{3+}, \mathrm{Yb}^{3+}$, absorb NIR light at $980 \mathrm{~nm}$ and efficiently emit light of higher energy in the red or green range of the visible spectrum. Besides this upconversion process, the emission of NIR light under 980-nm excitation is of special interest. This is due to the reduced absorption by haemoglobin and scattering when compared to light of shorter wavelengths (UV-VIS), which is absorbed within micrometers to a millimetre of tissue thickness [1]. The resulting deeper penetration depth into biological tissue enables the noninvasive investigation of tissue in deeper areas. Hilderbrand et al. report optical imaging using upconverting $\mathrm{Y}_{2} \mathrm{O}_{3}$ nanoparticles modified with poly(acrylic acid), poly(ethylene glycol), and a NIR emitting fluorophore [2]. Amine-modified rare-earth doped and codoped $\mathrm{Y}_{2} \mathrm{O}_{3}$ nanocrystals and nanorods for biomedical applications are described by Das and Tan [3]. Besides oxides, applications of $\mathrm{LaF}_{3}: \mathrm{Ln}^{3+}[4]$ or $\mathrm{NaYF}_{4}: \mathrm{Ln}^{3+}[5]$ nanoparticles as upconverting and NIR emitting phosphors in bioimaging are reported. In recent years, NIR-NIR bioimaging systems based on $\mathrm{Er}^{3+}$ doped $\mathrm{Y}_{2} \mathrm{O}_{3}$ nanoparticles have been developed in the group of K. Soga. The development of a NIR-IFBI (near-infrared in vivo fluorescence bioimaging) system using an InGaAs-CCD to detect the emitted light in the NIR wavelength region makes those phosphors promising candidates as biomarkers [6]. Besides the outstanding optical properties, magnetic properties of lanthanides are remarkable and make Ln-based inorganic (nano)structures promising candidates for applications as contrast agents in magnetic resonance imaging (MRI). Recently, the combination of luminescence showing lanthanide ions with a paramagnetic matrix, like $\mathrm{Fe}_{3} \mathrm{O}_{4}$ [7] or $\mathrm{Gd}_{2} \mathrm{O}_{3}$ [8-10], is of growing interest because both, 
the possibility of multicolour marking and time resolution of the luminescence and the high spatial resolution of MRI, could improve the efficiency of modern biomarkers. Therefore, we have recently investigated the suitability of gadolinium oxide nanostructures doped with $\mathrm{Er}^{3+}$ and $\mathrm{Yb}^{3+}$ ions as NIR-NIR fluorescent biomarkers, which may also be suitable as contrast agent in MRI. With regard to the application of metal and metal oxide nanostructures in biomedicine and bioimaging, surface modification is essential in order to provide the required biocompatibility and dispersability, for example, in ionic aqueous media. For example, functionalisation of nanoparticles with amino or carboxylic acids [11, 12], capping of quantum dots with biomolecules [13], coating with silica [14] and modification with polymers like poly(vinyl alcohol) [15], dextran, chitosan, or poly(ethylene glycol) are widely-used. Poly(ethylene glycol) (PEG) is chemically inert, provides terminal hydroxyl groups that can be used as anchors for functional groups, is nontoxic and highly solvent in water [16]. Further, grafting of nanostructures with PEG results in enhanced stability of suspensions due to steric repulsion. Surface modification with PEG (so-called PEGylation) is applied for quantum dots [17], metal [18, 19], and metal oxide $[20,21]$ nanostructures. PEG- $b$-PAAc (poly(ethylene glycol) poly(acrylic acid) block polymer) has been chosen because of the electrostatic adsorption of the poly(acrylic acid) group (PAAc) of the coblock polymer on the positively charged surface of the ceramic nanostructures [22].

Former investigation of the cytotoxicity of $\mathrm{Gd}_{2} \mathrm{O}_{3}$ : $\mathrm{Er}^{3+}, \mathrm{Yb}^{3+}$ towards macrophages revealed a toxic effect in case of bare nanostructures. However, viability could be improved by modifying the surface of the nanostructures with PEG- $b$ PAAc $[23,24]$. The cytotoxic effect on macrophages observed in case of bare nanostructures was deduced to the poor chemical durability of $\mathrm{Gd}_{2} \mathrm{O}_{3}$ under acidic conditions as found inside macrophages. The result is the release of toxic $\mathrm{Gd}^{3+}$ ions inducing cell death. Surface modification provided the required chemical durability of $\mathrm{Gd}_{2} \mathrm{O}_{3}$ reducing the $\mathrm{Gd}^{3+}$ release from nanostructures uptaken by macrophages. Firstly, variations of modification conditions (e.g., ultrasonic treatment versus stirring, modification time, and temperature) showed a strong effect on grafting rate, acidic resistivity, and $\zeta$-potential. Changes in FT-IR spectra in the wavenumber range from 500 to $1000 \mathrm{~cm}^{-1}$ in dependence from modification conditions led us propose the formation of a "gadolinium-PEG- $b$-PAAc-complex" on the gadolinium oxide nanostructure surface. The $\mathrm{pH}$ value of the PEG- $b$ PAAc solution that is used for modification is in the range of 3.5 to 4.0 , thus, corresponds to the critical range for chemical instability of $\mathrm{Gd}_{2} \mathrm{O}_{3}$. Consequently, a partial dissolution of $\mathrm{Gd}_{2} \mathrm{O}_{3}$ and an exposition of free $\mathrm{Gd}^{3+}$ on the nanostructure surface under acidic conditions are expected. In contrast, under basic conditions, most $\mathrm{Gd}^{3+}$ species are covered by $\mathrm{OH}^{-}$groups reducing the interaction with the PAAc group of the polymer.

In order to clarify the influence of modification conditions, potential formation of a "gadolinium-PEG- $b-P A A c$ complex" and to optimize modification conditions, we investigated the relationship between modification $\mathrm{pH}$ and physical as well as chemical properties of $\mathrm{Gd}_{2} \mathrm{O}_{3}: \mathrm{Er}^{3+}, \mathrm{Yb}^{3+}$ modified with PEG- $b$-PAAc in more detail.

\section{Results and Discussion}

\subsection{Material Synthesis and Characterization}

2.1.1. Morphology. Nanoscale $\mathrm{Gd}_{2} \mathrm{O}_{3}$ doped with $\mathrm{Er}^{3+}$ and $\mathrm{Yb}^{3+}$ ions was prepared by two different approaches, hydrothermal treatment and precipitation methods. This allows the variation of the morphology, such as spherical particles or rod-like structures. As shown by Wang and Li, the hydrothermal process easily provides various lanthanide hydroxide, $\operatorname{Ln}(\mathrm{OH})_{3}$, nanostructures including nanoparticles, nanotubes, nanosheets, or fullerene-like nanoparticles [25]. Herein, $\mathrm{pH}$ of the reaction mixture [26] as well as complexing agents [27] play an important role on the control over the aspect ratio of the $\mathrm{Ln}(\mathrm{OH})_{3}$ nanorods. $\mathrm{Ln}_{2} \mathrm{O}_{3}$ nanostructures can be obtained by a postthermal treatment, whereas shape and morphology are kept constant. We observed similar formation of nanorods with various aspect ratios by hydrothermal treatment of an aqueous gadolinium nitrate solution (doped with each $1 \mathrm{~mol} \% \mathrm{Er}^{3+}$ and $\mathrm{Yb}^{3+}$ ). Prior to the hydrothermal treatment $\left(200^{\circ} \mathrm{C}, 6 \mathrm{hrs}\right)$, the solutions were activated with either an aqueous potassium hydroxide $\left(\mathrm{KOH}_{\mathrm{aq}}\right)$ or ammonia solution. The variety of shape and aspect ratio of the obtained nanostructures (annealed at $900^{\circ} \mathrm{C}$ for $30 \mathrm{~min}$ ) is shown in the scanning electron micrographs in Figure 1.

Activation of the Ln solution with $4.5 \mathrm{~mL} 1 \mathrm{M} \mathrm{KOH}$ aq. results in nanorods with a homogeneous size distribution and an aspect ratio of approximately $12(\operatorname{Rods} 12$, Figure 1(a) [24]). The influence of the alkali concentration on morphology was investigated by adding 0.1 to $5.0 \mathrm{~mL}$ ammonia solution prior to the hydrothermal treatment. At low ammonia concentrations ( $V \leq 0.2 \mathrm{~mL}, \mathrm{pH}=6.6-6.8$ ) platelets of inhomogeneous size distribution (length $l$ and width $d$ : several $100 \mathrm{~nm}$ to $2 \mu \mathrm{m}$ ) are formed (Figures $1(\mathrm{~b})$ and $1(c))$. An increase in the ammonia concentration induces the formation of nanorods. A bimodal size distribution is obtained after activation with $0.35 \mathrm{~mL}$ ammonia $(\mathrm{pH}=7.1$, Figure 1(d)). Nanorods of $90 \mathrm{~nm}$ in width and an average length of $1.7 \mu \mathrm{m}$, resulting in an average aspect ratio of 18 are found. But also larger rod-like structures of approximately $400 \mathrm{~nm}$ in width and $4.2 \mu \mathrm{m}$ in length with an average aspect ratio of 11 are observed. Larger nanorods ( $l$ up to $4.5 \mu \mathrm{m}, d \sim 400-500 \mathrm{~nm}$, aspect ratio $\sim 7-9$ ) are obtained in case of $0.5 \mathrm{~mL}$ ammonia $(\mathrm{pH}=8.7$, Figure $1(\mathrm{e}))$. Further increase in the amount of ammonia reduces the size of the nanostructures: the addition of $1.0 \mathrm{~mL}$ ammonia $(\mathrm{pH}$ $=9.2$ ) results in nanorods of up to $1.5 \mu \mathrm{m}$ in length and $100 \mathrm{~nm}$ in width (average aspect ratio: 11) (Figure 1(f)). Further decrease in size is observed for the addition of $2 \mathrm{~mL}$ ammonia ( $\mathrm{pH}=10.3$, average $l \sim 440 \mathrm{~nm}, d \sim 80 \mathrm{~nm}$, aspect ratio: 6) (Figure $1(\mathrm{~g})$ ). Almost no changes in morphology are observed at even higher ammonia concentrations $(2 \mathrm{~mL}$ $\leq V \leq 5 \mathrm{~mL}, \mathrm{pH}=10.3-10.9$, Figures $1(\mathrm{~h})$ and $1(\mathrm{i}))$. Comparing Figures $1(\mathrm{f})$ and $1(\mathrm{j})$, which both show powders 


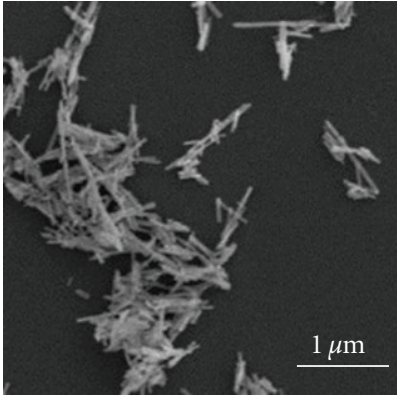

(a)

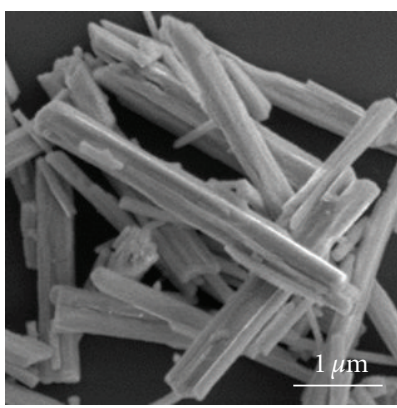

(e)

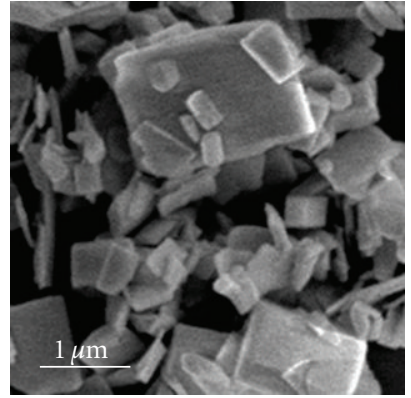

(b)

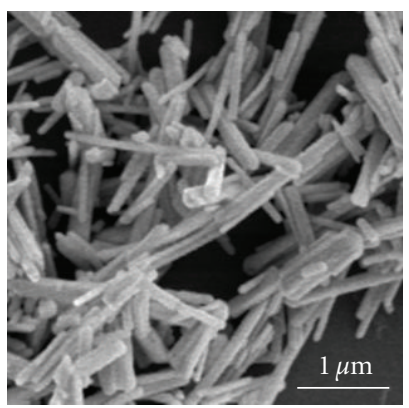

(f)

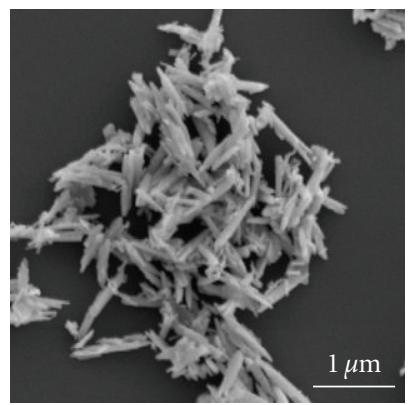

(i)

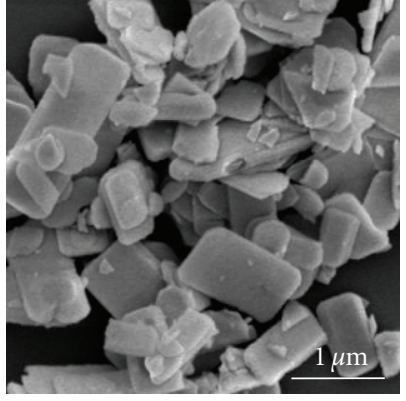

(c)

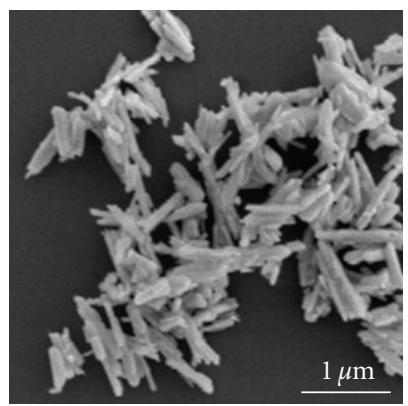

(g)

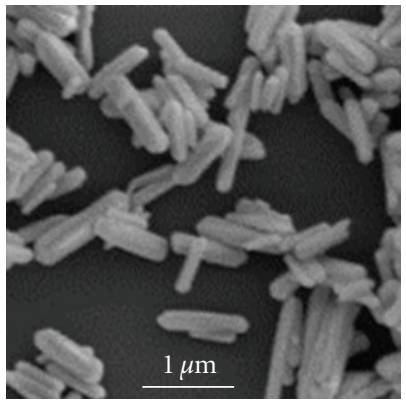

(j)

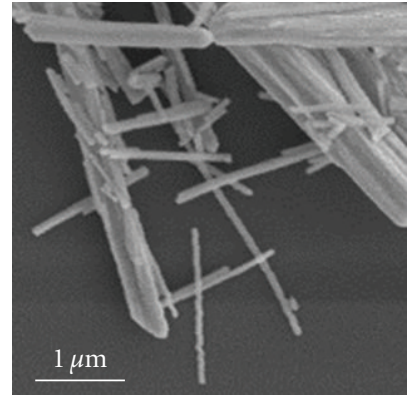

(d)

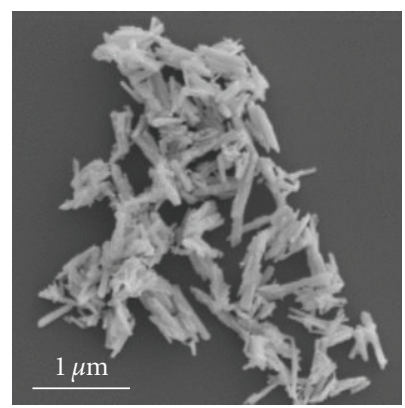

(h)

FIGURE 1: Scanning electron micrographs of $\mathrm{Gd}_{2} \mathrm{O}_{3}: \mathrm{Er}^{3+}, \mathrm{Yb}^{3+}$ nanorods by hydrothermal synthesis using various precipitation agents: (a) $\mathrm{KOH}_{\text {aq. }}$ (Rods12) or ammonia: (b) $0.1 \mathrm{~mL}$, (c) $0.2 \mathrm{~mL}$, (d) $0.35 \mathrm{~mL}$, (e) $0.5 \mathrm{~mL}$, (f) $1.0 \mathrm{~mL}$, (g) $2.0 \mathrm{~mL}$, (h) $3.0 \mathrm{~mL}$, (i) $5.0 \mathrm{~mL}$. (j) Influence of mixing order, $1 \mathrm{~mL}$ ammonia (Rods5).

obtained by activation with $1 \mathrm{~mL}$ ammonia, the influence of the mixing order becomes obvious. Generally, 0.1 to $5 \mathrm{~mL}$ ammonia solution was added to the aqueous Ln solution. In contrast, powders shown in Figure 1(j) have been prepared by adding an aqueous lanthanide solution $(V=9 \mathrm{~mL})$ to a diluted ammonia solution ( $1 \mathrm{~mL}$ ammonia in $20 \mathrm{~mL} \mathrm{H}_{2} \mathrm{O}$ ) during rigorous stirring. The latter case results in a much more homogeneous size distribution with an average length of $660 \mathrm{~nm}$ and width of $160 \mathrm{~nm}$ (average aspect ratio: 4-5, Rods5 [28]). Hence, precipitation by adding the Ln solution into a diluted alkaline (precipitant) solution under stirring induces a more homogenous precipitation process, which results in the uniform growth of nanorods with a monodispersed size distribution during the hydrothermal treatment.

As reported previously [28], spherical nanostructures can be obtained by precipitation methods without further hydrothermal treatment. Particles of inhomogeneous morphology and size $(d \sim 100 \mathrm{~nm}$ to $1 \mu \mathrm{m}$, Figure 2(a)) are obtained by alkaline precipitation (AP) using sodium carbonate, $\mathrm{Na}_{2} \mathrm{CO}_{3}$, as precipitation agent (ParticlesAP). Enzymatic precipitation (EP) results in smaller particles of less than $100 \mathrm{~nm}$ in diameter (ParticlesEP). In EP, the enzyme urease is used in order to decompose urea at room temperature providing $\mathrm{NH}_{4}{ }^{+}$, which reacts as precipitant [29]. Due to the reduced particle size and the absence of any surfactant during synthesis a high tendency for the formation of agglomerations is observed (Figure 2(b)). In order to avoid agglomeration and to improve homogeneity of the nanoparticles, surfactant-free and surfactant-assisted homogeneous precipitation (HP) of $\mathrm{Gd}_{2} \mathrm{O}_{3}$ was affected as originally described by Matijević and Hsu [30]. The obtained nanoparticles are not agglomerated and show a diameter of approximately $300 \mathrm{~nm}$ (Figure 2(c)). However, by the proposed surfactant-free method, morphology control is difficult, may result in inhomogeneous morphology and size distribution as reported in literature [31]. We observed 


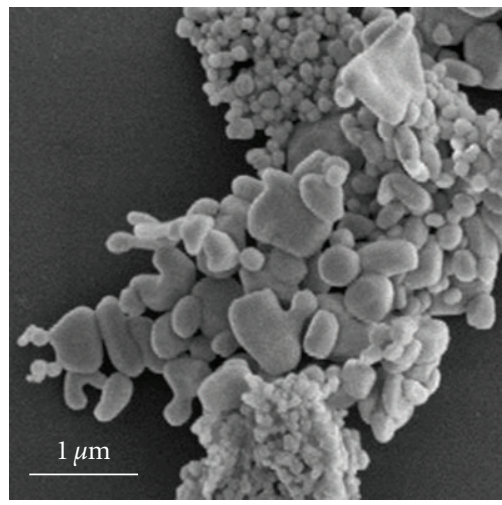

(a)

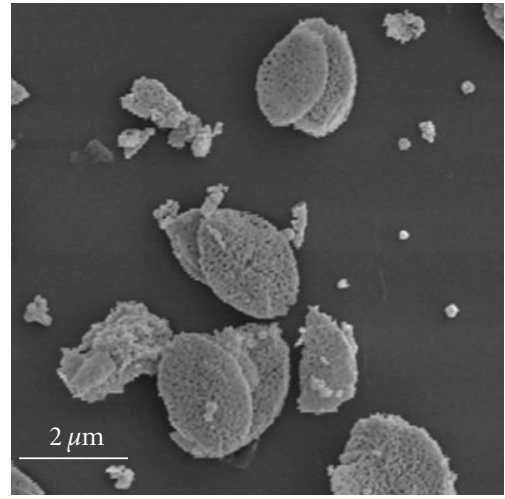

(d)

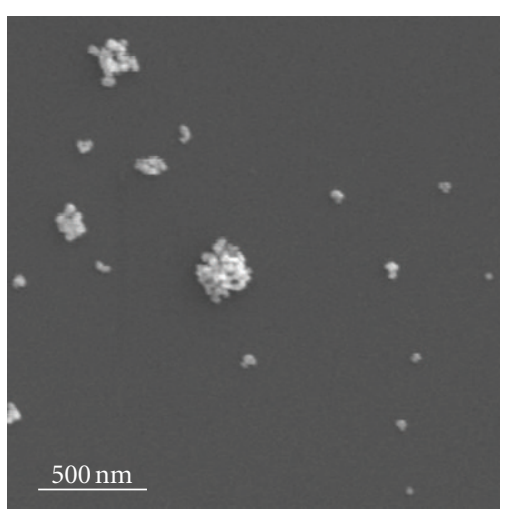

(b)

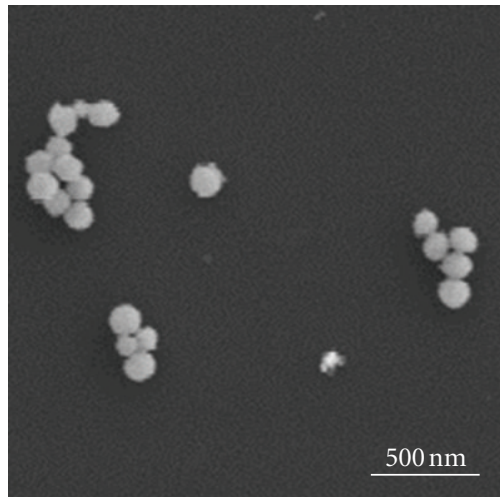

(e)

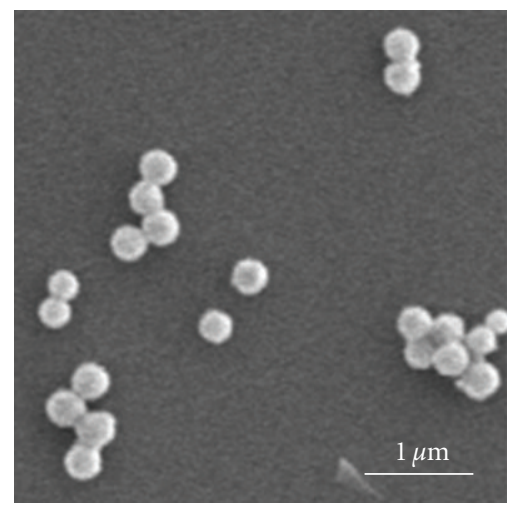

(c)

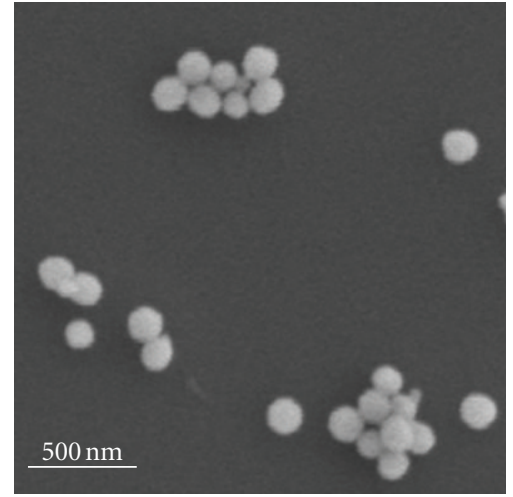

(f)

FIgure 2: Scanning electron micrographs of $\mathrm{Gd}_{2} \mathrm{O}_{3}: \mathrm{Er}^{3+}, \mathrm{Yb}^{3+}$ particles obtained by precipitation methods: (a) ParticlesAP, (b) ParticlesEP, (c) ParticlesHP, (d) FlakesHP, (e) ParticlesHP-PEG and (f) ParticlesHP-CTAB.

the formation of flake-like structures (FlakesHP) of about $2 \mu \mathrm{m}$ in length and $1.5 \mu \mathrm{m}$ in width (Figure 2(d)). Those flakes are built up by smaller particles, which were similarly reported by Park et al. and which were assigned to strong bonds between the aggregates due to thermal decomposition of the precursor gadolinium carbonate [31]. The growth of flake-like structures can be overcome by the addition of PEG-6000 or CTAB (cetyltrimethylammonium bromide) [23] resulting in smaller nanoparticles when compared to the surfactant-free method with diameters of about 150$120 \mathrm{~nm}$ (ParticlesHP-PEG, Figure 2(e), ParticlesHP-CTAB, Figure 2(f)). Water at $85^{\circ} \mathrm{C}$ is highly active for diffusion processes, which drives the growth of particles. When $\mathrm{CTAB}$ or PEG is added into the solution, diffusion processes are inhibited and the formation of agglomerations can be suppressed. Further, reduced agglomeration is ascribed to the adsorption of CTAB molecules on the formed hydroxide precipitates by $\mathrm{Zhu}$ et al. describing the formation of $\mathrm{Nd}(\mathrm{OH})_{3}$ nanoparticles by microemulsion method using CTAB for morphology control [32]. Hereby, adsorption of CTAB molecules on the surface planes of the formed lanthanide hydroxide can inhibit the aggregation of nanoparticles. Moreover, an increase in particle size with increasing stirring time is reported. This is deduced to an enhanced Brownian motion of the microemulsion droplets, leading to increased interaction between droplets and therefore easy aggregation.
In agreement with this, we observed a more likely formation of flake-like agglomerations of $\mathrm{Gd}_{2} \mathrm{O}_{3}: \mathrm{Er}^{3+}, \mathrm{Yb}^{3+}$ when the reaction time exceeds $30 \mathrm{~min}$ even in presence of CTAB. In contrast to observations by Zhu et al., but in agreement with Yue et al. [33], CTAB concentrations in the range of 0.3 to $33.3 \mathrm{mmol} / \mathrm{L}$ had no influence on size or morphology of the resultant material.

Scheme 1 gives an overview of the used synthesis routes and variations as well as the morphology and size of the resultant nanostructures.

2.1.2. Crystallinity and Phase. Powder X-ray diffraction (XRD) analysis on powders obtained by hydrothermal treatment revealed crystalline gadolinium hydroxide, $\mathrm{Gd}(\mathrm{OH})_{3}$, when $0.35 \mathrm{~mL}$ or a higher volume of ammonia solution was added ( $\mathrm{pH} \geq 7.1$, Figure $3(\mathrm{a}))$. In analogy with the changes in morphology, different XRD patterns are obtained for powders prepared at lower ammonia concentrations. Patterns recorded for powders obtained by addition of 0.1 or $0.2 \mathrm{~mL}$ ammonia solution ( $\mathrm{pH}$ : 6.6-6.8) show peaks that do not match with the characteristic pattern for $\mathrm{Gd}(\mathrm{OH})_{3}$. However, we could not doubtlessly determine the obtained phase. The formation of crystalline $\mathrm{Gd}(\mathrm{OH})_{3}$ at $\mathrm{pH}$ higher than 7 is in agreement with the stability of lanthanide hydroxides in alkaline solution, but instability in acid solutions in which 


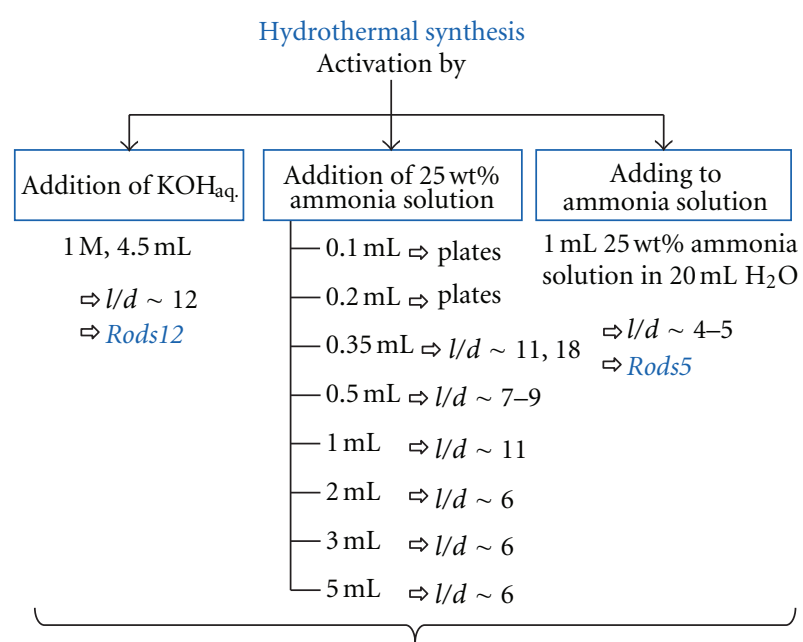

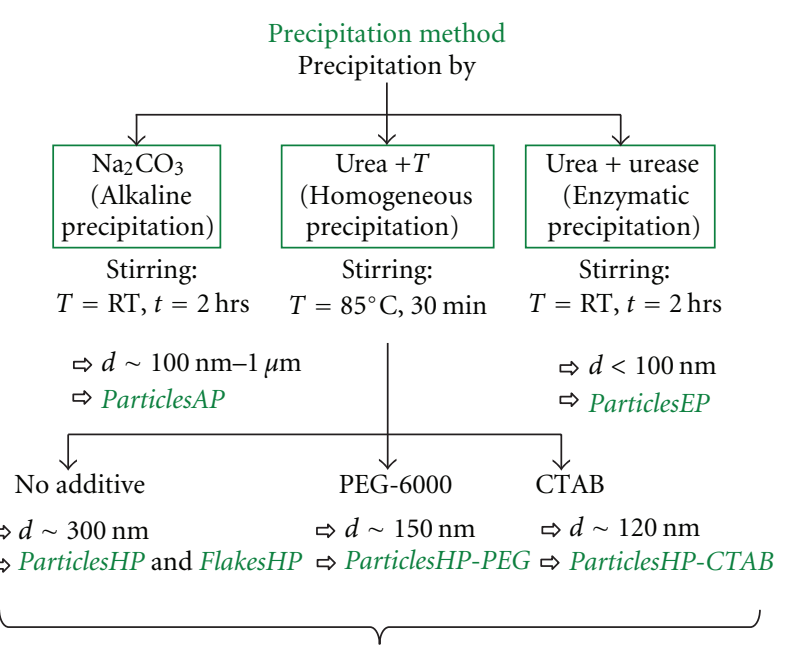

Autoclave: $T=200^{\circ} \mathrm{C}, t=6-12 \mathrm{hrs} \longrightarrow \mathrm{Gd}(\mathrm{OH})_{3}: \mathrm{Er}^{3+}, \mathrm{Yb}^{3+} \longrightarrow 900^{\circ} \mathrm{C}, 30 \mathrm{~min} \longleftarrow$ Amorphous powders

$\downarrow$ $\mathrm{Gd}_{2} \mathrm{O}_{3}: \mathrm{Er}^{3+}, \mathrm{Yb}^{3+}$

Dispersion in $\mathrm{H}_{2} \mathrm{O}$ $\downarrow$

Sonication: $t=30 \mathrm{~min}$

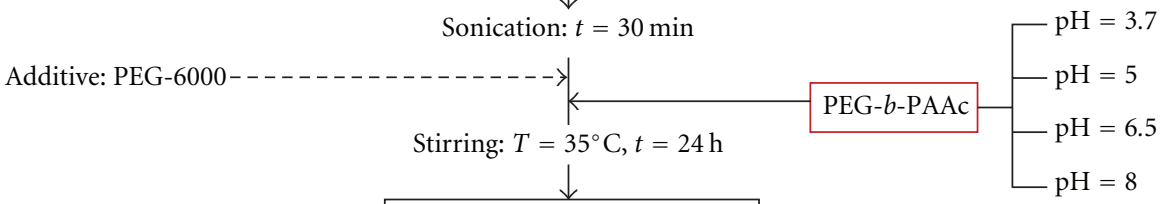

$\mathrm{PEG}-b$-PAAc- $\mathrm{Gd}_{2} \mathrm{O}_{3}: \mathrm{Er}^{3+}, \mathrm{Yb}^{3+}$

Scheme 1: Overview of the used synthesis routes for the preparation of $\mathrm{Gd}_{2} \mathrm{O}_{3}: \mathrm{Er}^{3+}, \mathrm{Yb}^{3+}$ nanostructures and their modification with PEG$b$-PAAc.

they dissolve as the corresponding cations [34]. Independent from alkaline concentration, all as-prepared powders could be transformed into the oxide phase, $\mathrm{Gd}_{2} \mathrm{O}_{3}$, by postthermal treatment at $900^{\circ} \mathrm{C}$ for $30 \mathrm{~min}$ (Figure 3(b), graphs $\mathrm{B}$ and $\mathrm{C})$. In fact, those high temperatures $\left(900^{\circ} \mathrm{C}\right)$ are not necessary for transformation of $\mathrm{Gd}(\mathrm{OH})_{3}$ into $\mathrm{Gd}_{2} \mathrm{O}_{3}$. Lower annealing temperatures, such as $600^{\circ} \mathrm{C}$, are sufficient to induce crystallization of the oxide phase (Figure 3(b), graph A). The reason for the postthermal treatment at such high temperatures is that at least $900^{\circ} \mathrm{C}$ are necessary for the elimination of residual hydroxyl or carbonate groups which may quench the photoluminescence of $\mathrm{Gd}_{2} \mathrm{O}_{3}: \mathrm{Er}^{3+}, \mathrm{Yb}^{3+}$.

Due to crystallization of gadolinium hydroxide in the hexagonal lattice ( $a=6.3290 \AA, b=6.3290 \AA, c=3.6310 \AA$ ) no templates are required to synthesize elongated structures. Consequently, the hydrothermal treatment leads to a rod-like morphology of $\mathrm{Gd}_{2} \mathrm{O}_{3}: \mathrm{Er}^{3+}, \mathrm{Yb}^{3+}$. The anisotropic growth is governed by crystal chemistry and chemical potential in solution [35-38]. The chemical potential is tuneable by $\mathrm{pH}$ value of the reaction mixture, whereas a higher chemical potential favours the one-dimensional growth. As a result nanorods are obtained at addition of at least $0.35 \mathrm{~mL}$ ammonia, while at lower ammonia amount (lower $\mathrm{pH}$ ) the 1-dimensional growth is less supported resulting in platelike structures (Figures 1(b) and 1(c)). For higher $\mathrm{OH}^{-}$ concentrations lower aspect ratios are expected as explained in the formation mechanism of 1-dimensional $\mathrm{Ln}(\mathrm{OH})_{3}$ structures proposed by Wang and $\mathrm{Li}[36,37]$ and Yang et al. [26]. In agreement with the proposed formation mechanism we observe a strengthening of the (110) peak in the XRD pattern of $\mathrm{Gd}(\mathrm{OH})_{3}: \mathrm{Er}^{3+}, \mathrm{Yb}^{3+}$ obtained by addition of $0.35 \mathrm{~mL}$ ammonia solution $(V$ (ammonia $)=0.35 \mathrm{~mL}$ : $\mathrm{I}_{(110)} / \mathrm{I}_{(101)}=2.4 ; V$ (ammonia) $\left.=5 \mathrm{~mL}: \mathrm{I}_{(110)} / \mathrm{I}_{(101)}=0.8\right)$. This strengthening represents the favoured growth direction along the $\mathrm{c}$-axis, resulting in the high aspect ratio of 18 observed in SEM (Figure 1(d)). With an increasing amount of ammonia inducing a reduced aspect ratio $(l / d \sim 6)$ this strengthening is less pronounced.

As-prepared powders from hydrothermal synthesis consist of crystalline $\mathrm{Gd}(\mathrm{OH})_{3}$. In contrast, precipitation methods always lead to amorphous powders requiring a postthermal treatment to induce crystallization. X-ray diffraction patterns recorded on annealed powders obtained by enzymatic, alkaline, and CTAB-assisted homogeneous precipitation confirm the crystallization of $\mathrm{Gd}_{2} \mathrm{O}_{3}: \mathrm{Er}^{3+}, \mathrm{Yb}^{3+}$ (Figure 3(c)). Crystal sizes determined by Scherrer equation increase from $31 \mathrm{~nm}$ (ParticlesEP) to $43 \mathrm{~nm}$ (ParticlesHP$C T A B)$ to $61 \mathrm{~nm}$ (ParticlesAP). A crystal size of $38 \mathrm{~nm}$ was determined for the FlakesHP. Even though the particles are not single crystals, but are built up by several crystallites, the smaller calculated crystal size in case of ParticlesEP reflects the trend for a smaller average particle size observed in SEM. 


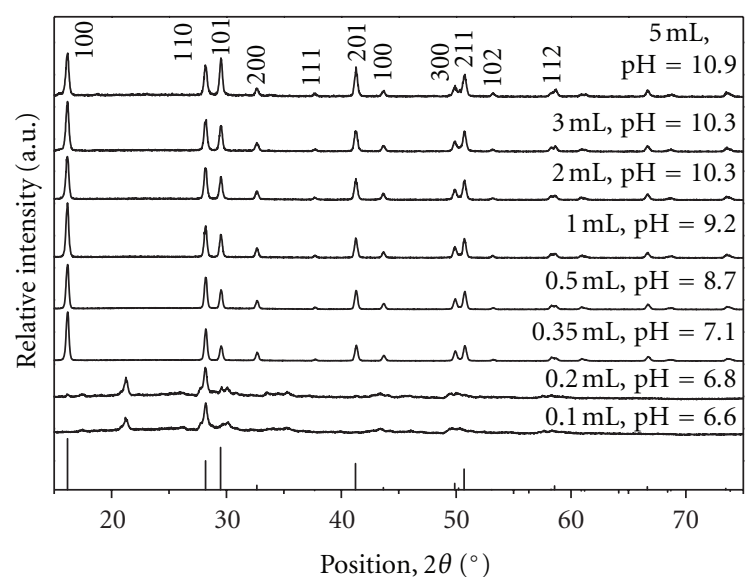

(a)

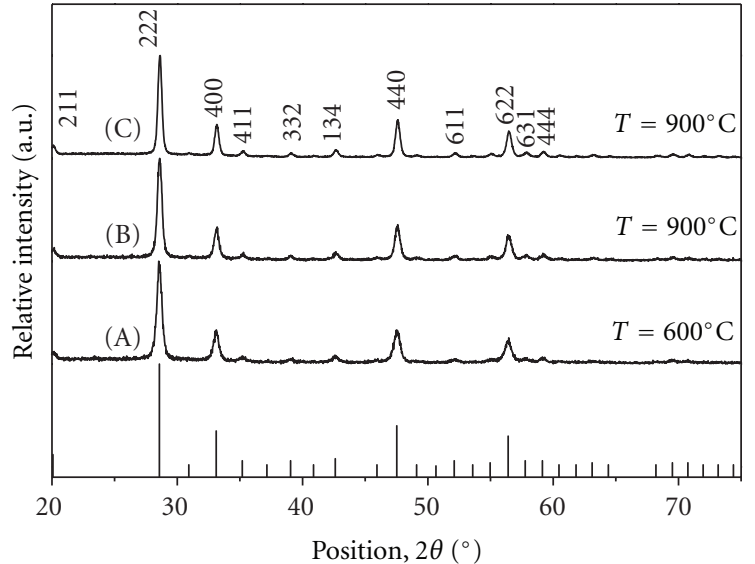

(b)

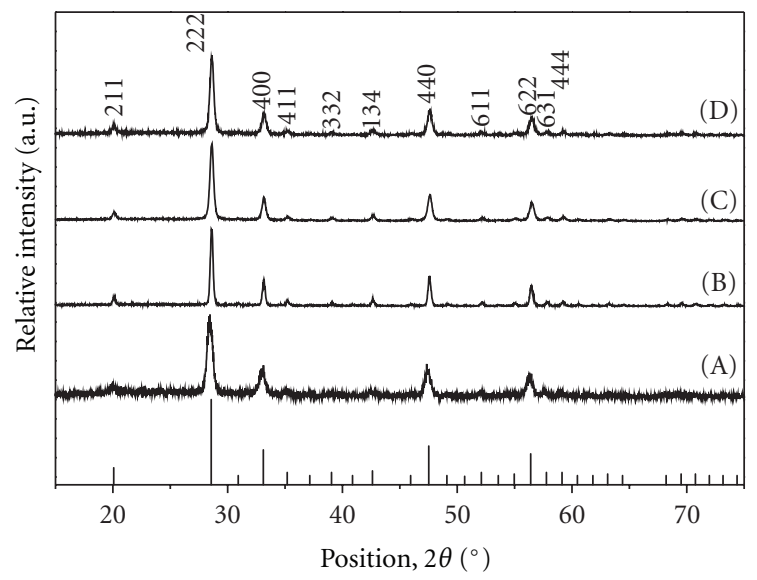

(c)

FIGURE 3: XRD patterns of (a) as-prepared powders obtained by hydrothermal synthesis with various ammonia concentrations, (b) annealed powders (A, B: Rods12, C: Rods5), (c) powders obtained by precipitation methods (A: ParticlesEP, B: ParticlesAP, C: ParticlesHP-CTAB, D: FlakesHP). Reference: (a) $\mathrm{Gd}(\mathrm{OH})_{3}$, [83-2037]; (b), (c) $\mathrm{Gd}_{2} \mathrm{O}_{3}$, [12-0797].

2.1.3. Optical Properties. With regard to potential applications as luminescent biomarkers, optical properties of $\mathrm{Gd}_{2} \mathrm{O}_{3}: \mathrm{Er}^{3+}, \mathrm{Yb}^{3+}$ were investigated [28]. All samples show the characteristic $\mathrm{Er}^{3+} \mathrm{f}-\mathrm{f}$ transition peaks for upconversion emission under $980 \mathrm{~nm}$ excitation. Green emission corresponds to ${ }^{4} \mathrm{H}_{11 / 2} \rightarrow{ }^{4} \mathrm{I}_{15 / 2}(525 \mathrm{~nm})$ and ${ }^{4} \mathrm{~S}_{3 / 2} \rightarrow{ }^{4} \mathrm{I}_{15 / 2}$ $(561 \mathrm{~nm})$ transitions. The red emission band is referred to the ${ }^{4} \mathrm{~F}_{9 / 2} \rightarrow{ }^{4} \mathrm{I}_{15 / 2}(660 \mathrm{~nm}, 677 \mathrm{~nm})$ transition (Figure $4(\mathrm{a}))$. Enhanced emission intensity and peak resolution are observed for nanoparticles when compared to nanorods. This may be due to different powder densities or carbonate or hydroxide impurities. Figure 4(a) also shows the emission spectra recorded in the NIR wavelength range with a peak of maximum intensity at $1540 \mathrm{~nm}$, which can be assigned to the ${ }^{4} \mathrm{I}_{13 / 2} \rightarrow{ }^{4} \mathrm{I}_{15 / 2}$ transition of $\mathrm{Er}^{3+}$. As mentioned earlier, NIR emission is particularly interesting with regard to new NIR-based bioimaging devices [39].

As the interpretation of the emission intensities is not trivial, we here discuss the relation between the red $(660 \mathrm{~nm}$, $\left.{ }^{4} \mathrm{~F}_{9 / 2} \rightarrow{ }^{4} \mathrm{I}_{15 / 2}\right)$ and the green $\left(560 \mathrm{~nm},{ }^{4} \mathrm{~S}_{3 / 2} \rightarrow{ }^{4} \mathrm{I}_{15 / 2}\right)$ ratio of the emission spectra. Comparing the red-to-green ratio of particles obtained by enzymatic, alkaline, and CTAB-assisted homogeneous precipitation, ParticlesEP and ParticlesHP$C T A B(d \sim 120-150 \mathrm{~nm})$ show a higher red-to-green ratio than ParticlesAP ( $d \sim 100 \mathrm{~nm}$ to $\mu \mathrm{m}$ ) (Figure $4(\mathrm{~b}))$. In fact, a stronger phonon interaction of the rare-earth ions is known to be often found for smaller particle size resulting in the increased emission of red light $[40,41]$. With increasing particle size the specific surface area decreases compared to the volume. Hence, there are less $\mathrm{Ln}^{3+}$ that are affected on the surface. Thus, rare-earth ions doped into larger ParticlesAP show less phonon interaction and consequently the ratio between red and green light shifts towards the green range. A further aspect taking influence on the red-to-green ratio is the hydroxyl content in the investigated powders. In general, upconversion emission efficiency from lanthanide ions doped into a ceramic host is strongly influenced by organic ligands or solvent molecules, such as groups with high energy vibrational mode $\left(\mathrm{OH}, \mathrm{NH}_{2}\right)$ located close to the light-emitting lanthanide ions resulting in quenching of the upconversion emission [42]. In order to determine the hydroxyl content, FT-IR spectra were recorded on the 


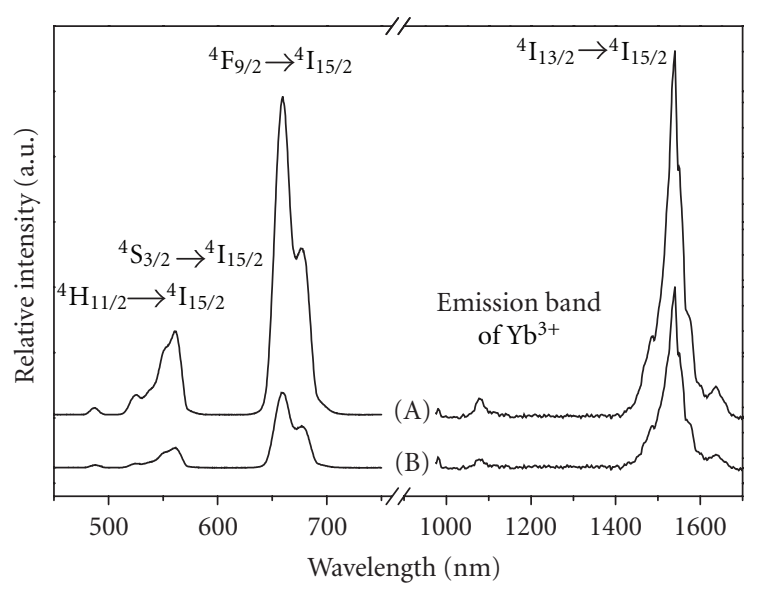

(a)

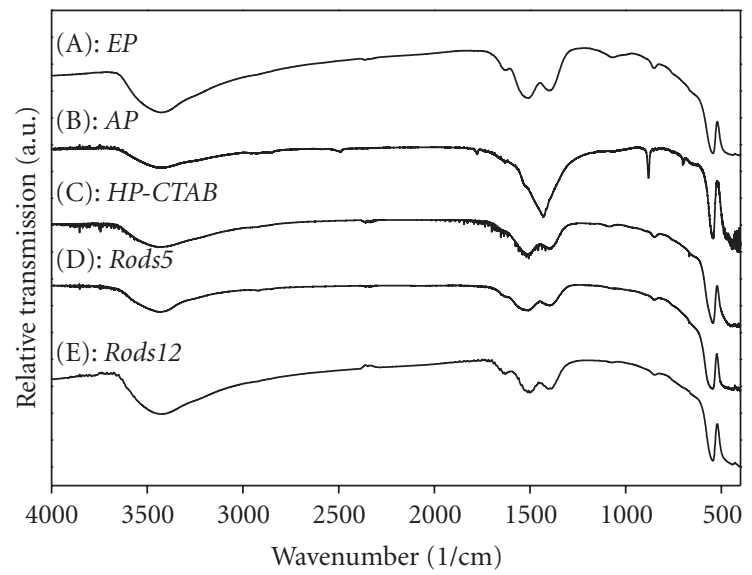

(c)

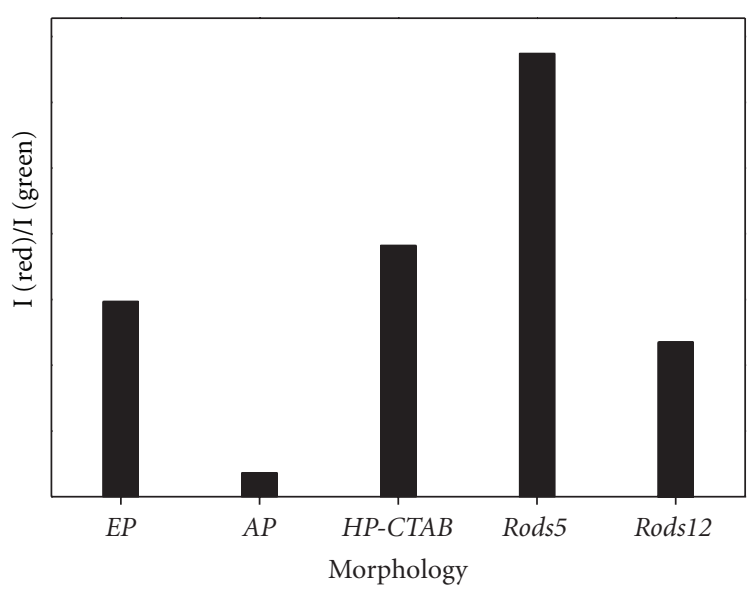

(b)

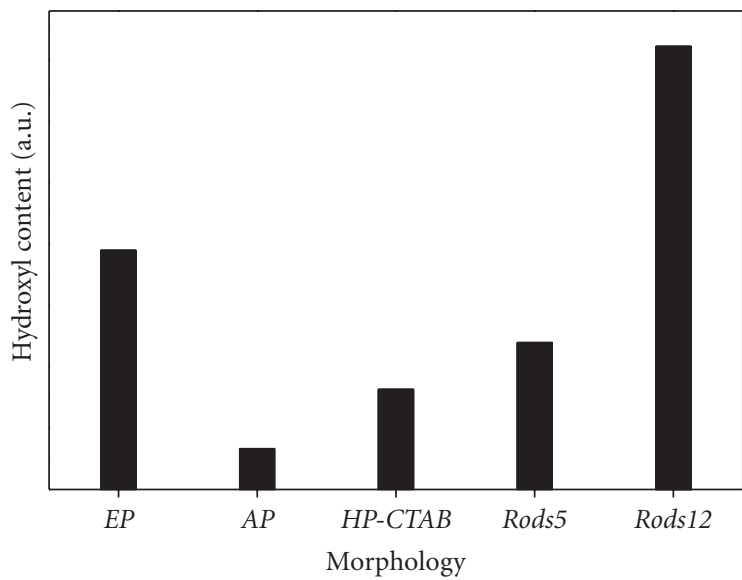

(d)

Figure 4: (a) Upconversion $\left(\lambda_{\mathrm{ex}}=980 \mathrm{~nm}, P_{\text {Laser }}=600 \mathrm{~mW}\right)$ and NIR $\left(\lambda_{\mathrm{ex}}=980 \mathrm{~nm}, P_{\mathrm{Laser}}=100 \mathrm{~mW}\right)$ emission of ParticlesHP-CTAB (A) and Rods5 (B) (Similar spectra have been obtained for all other samples). (b) Ratio between the red and green emission intensities. (c) Normalized FT-IR spectra recorded on (A) ParticlesEP, (B) ParticlesAP, (C) ParticlesHP-CTAB, (D) Rods5 and (E) Rods12. (d) Peak area at $3500 \mathrm{~cm}^{-1}$ representing the hydroxyl content of the samples.

samples. As obvious from the obtained spectra (Figures 4(c) and 4(d)) the hydroxyl content in ParticlesHP-CTAB and ParticlesEP is higher than in ParticlesAP. The broad band in the range $1200-1700 \mathrm{~cm}^{-1}$ recorded on ParticlesAP indicates the presence of water molecules on the nanoparticle surface, but the hydroxyl content in the structures is lower compared to ParticlesHP-CTAB and ParticlesEP. The sharp peak at $880 \mathrm{~cm}^{-1}$ is associated to $\mathrm{CO}_{3}{ }^{2-}$ [43] originating from the use of $\mathrm{Na}_{2} \mathrm{CO}_{3}$ as precipitant in alkaline precipitation method. In general, the red light emitting ${ }^{4} \mathrm{~F}_{9 / 2}$ state is mainly produced by quenching of the green light emitting ${ }^{4} \mathrm{~S}_{3 / 2}$ state [44]. Accordingly, the higher content in $\mathrm{OH}^{-}$groups leads to quenching of the green emission while the red emission is maintained. This then results in the observed higher red-togreen ratio of ParticlesEP and ParticlesHP-CTAB compared to ParticlesAP. On the other hand, even though Rods12 show much higher hydroxyl content than Rods5, the red-to-green ratio is enhanced in case of Rods5. The lower red-to-green ratio in case of Rods 12 cannot be explained by the residual hydroxyl content, however, we suggest the higher content in residual carbonate groups $\left(1400 \mathrm{~cm}^{-1}, 1510 \mathrm{~cm}^{-1}\right)$ and the presence of water molecules (peak at $1630 \mathrm{~cm}^{-1}$ associated with $\mathrm{H}-\mathrm{O}-\mathrm{H}$ bending of water [45]) determined in Rods12 to be the reason for the stronger quenching effect.

2.2. Surface Modification with PEG-b-PAAc. ParticlesHP$C T A B$ and Rods5 were chosen for modification with PEG$b$-PAAc. An aqueous suspension of those nanostructures was stirred at $35^{\circ} \mathrm{C}$ for $24 \mathrm{hrs}$ after the addition of an aqueous PEG- $b$-PAAc solution, whose $\mathrm{pH}$ was set to $3.7,5.0,6.5$, or 8.0.

The $\zeta$-potential of bare $\mathrm{Gd}_{2} \mathrm{O}_{3}: \mathrm{Er}^{3+}, \mathrm{Yb}^{3+}$ nanostructures dispersed in distilled water [24] decreases from $+21.8 \mathrm{mV}$ (ParticlesHP-CTAB) and $+18.5 \mathrm{mV}$ (Rods5) to $-35.74 \mathrm{mV}$ (ParticlesHP-CTAB) and $-30.0 \mathrm{mV}$ (Rods5) when the $\mathrm{pH}$ of the dispersion increases from 5 to 12 . The isoelectric point was found to be at $\mathrm{pH}=8.6$ (ParticlesHP-CTAB) and 8.4 (Rods5). Modification with PEG- $b$-PAAc is based on the electrostatic adsorption of the poly(acrylic acid) group 


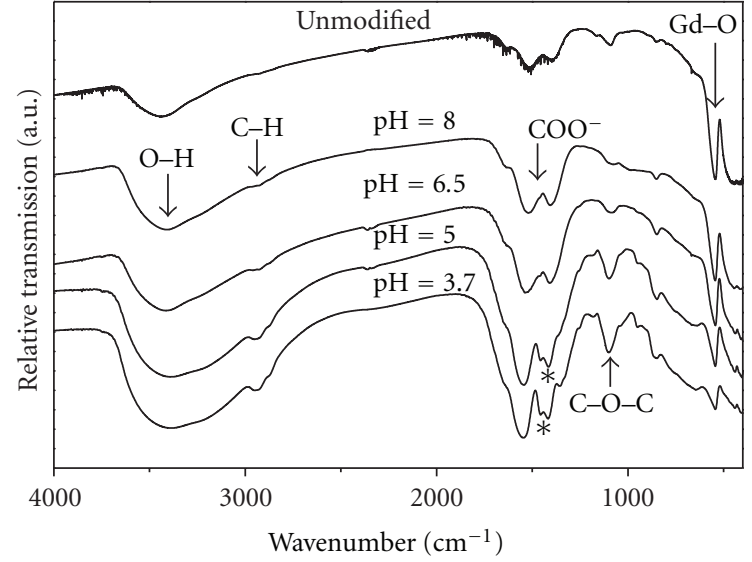

(a)

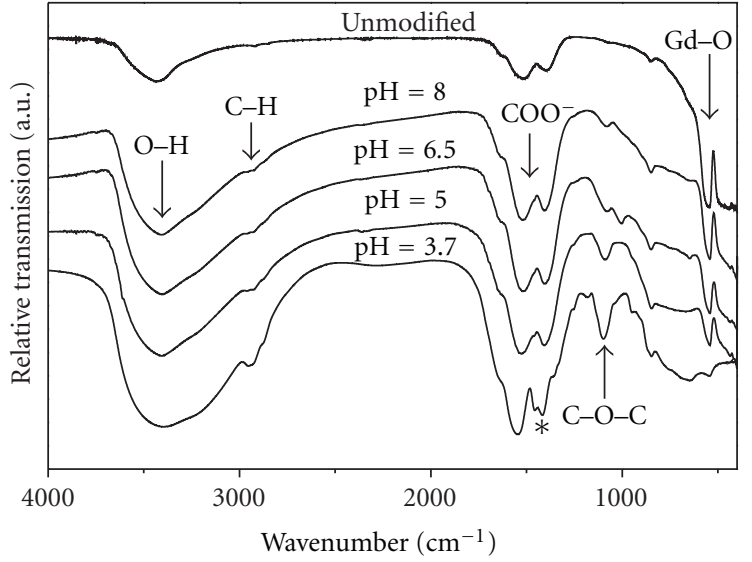

(b)

FIgURE 5: FT-IR spectra recorded on unmodified and PEG- $b$-PAAc modified (a) ParticlesHP-CTAB and (b) Rods5 showing the influence of modification $\mathrm{pH}$.

(PAAc) of the coblock polymer on the positively charged surface of the nanostructures. Previously [23, 28], nanostructures have been modified by addition of a PEG- $b$-PAAc solution of $\mathrm{pH}$ 3.7. Under those conditions surface charge is sufficiently positive to ensure the electrostatic adsorption as shown by $\zeta$-potential measurements. An increase in $\mathrm{pH}$ of the nanostructure suspension results in a decrease of the surface charge reaching the isoelectrical point at $\mathrm{pH} \sim 8.5$. As a consequence, reduced adsorption rate is expected in case of modification using PEG- $b$-PAAc solutions of higher $\mathrm{pH}$.

2.2.1. FT-IR Spectroscopy. FT-IR spectra recorded on bare and modified ParticlesHP-CTAB and Rods 5 are presented in Figure 5. All spectra show an adsorption peak at $545 \mathrm{~cm}^{-1}$, which is assigned to the metal-oxygen bonds in gadolinium oxide. In case of modified samples, a broad band due to $\mathrm{O}-\mathrm{H}$ groups in the range of $3500 \mathrm{~cm}^{-1}$ and a shoulder at $1640 \mathrm{~cm}^{-1}$ assigned to $\mathrm{H}-\mathrm{O}-\mathrm{H}$ bending of water result from the modification in aqueous medium. Peaks at 2900 and $1100 \mathrm{~cm}^{-1}$ can be assigned to $\mathrm{C}-\mathrm{H}$ asymmetric stretching and $\mathrm{C}-\mathrm{O}-\mathrm{C}$ stretching in PEG [46]. Peaks of less intensity are observed at 1347 and $950 \mathrm{~cm}^{-1}$, which are due to $\mathrm{CH}_{2}$ wagging motion as well as $\mathrm{CH}_{2}$ rocking vibrations [47]. Those peaks are also observed in the FT-IR spectrum recorded on pure PEG- $b$-PAAc (provided in supporting information). This confirms the presence of PEG- $b$-PAAc on the surface of $\mathrm{Gd}_{2} \mathrm{O}_{3}: \mathrm{Er}^{3+}, \mathrm{Yb}^{3+}$ nanostructures. The sharp and intensive peak at $1730 \mathrm{~cm}^{-1}$ observed for pure PEG- $b$ PAAc, originating from carboxylic acidic groups $(-\mathrm{COOH})$, disappears in spectra recorded on modified samples. Instead, two bands at 1523 and $1406 \mathrm{~cm}^{-1}$ appear. Those are related to carboxylate $\left(-\mathrm{COO}^{-}\right)$stretches [48] giving a further confirmation for surface modification.

With decreasing modification $\mathrm{pH}$ intensities of the peaks assigned to $\mathrm{C}-\mathrm{H}, \mathrm{C}-\mathrm{O}-\mathrm{C}$, as well as $-\mathrm{COO}^{-}$increase. This increase indicates a higher amount of PEG- $b$-PAAc on the nanostructure surface. Further, in case of $\mathrm{pH} 5$ or lower a splitting of the peak at $1406 \mathrm{~cm}^{-1}$ into two peaks at
1419 and $1453 \mathrm{~cm}^{-1}$ is observed (marked with an asterisk). Investigating the formation of complex of copper with poly(acrylic acid), Allan et al. report peaks at a similar wavenumber range $\left(1554,1451\right.$, and $\left.1413 \mathrm{~cm}^{-1}\right)$ and assign them to the $v\left(\mathrm{COO}^{-}\right)$group, which has complexed to the copper ion [49]. Hence, formation of a gadolinium-PEG-bPAAc-complex (Scheme 2) is proposed to be the origin of the here observed peak splitting. While the peak intensity of bands, which are characteristic for the polymer, is increasing with decreasing $\mathrm{pH}$, the $\mathrm{Gd}-\mathrm{O}$ band is less pronounced and broadened. Reference measurements on gadolinium acetate tetrahydrate (FT-IR spectrum provided in Supplementary Material available online at doi: 10.1155/2012/748098) reveal a broad band at wavenumber range 850 to $550 \mathrm{~cm}^{-1}$. The exhibition of such a band is a potential reason for the broadening observed in the spectra recorded on samples modified with PEG- $b$-PAAc solutions of $\mathrm{pH} 5$ or lower and supports the suggested complex formation.

2.2.2. TG-DTA Analysis. For further determination of the amount of PEG- $b$-PAAc on the surface of the nanostructures, TG-DTA analysis was performed from 20 to $900^{\circ} \mathrm{C}$ (under air). Endothermic peaks in the range of 40 to $80^{\circ} \mathrm{C}$ in the DTA curves (not shown here) are assigned to the loss of absorbed water on the nanostructure surface. Exothermic peaks in the range of 350 to $390^{\circ} \mathrm{C}$ are assigned to the combustion of organic groups, namely, PEG- $b$-PAAc. Herein, a shift of the exothermic peaks to lower temperatures is observed with increasing modification $\mathrm{pH}$. TG curves (not shown here) show a two-step mass loss at equivalent temperatures with main mass loss $\Delta m_{2}$ in the temperature range from 200 to $500^{\circ} \mathrm{C}$, which is taken as representative for the grafting rate with PEG- $b$-PAAc (Table 1) [50]. In analogy to DTA characteristics, $\Delta m_{2}$ changes with modification $\mathrm{pH}$. With increasing modification $\mathrm{pH}$ the temperature range for $\Delta m_{2}$ is broadened and less sharp. The grafting rate $\left(\Delta m_{2} /\right.$ residual mass $)$ is decreasing from $0.31(\mathrm{pH}=3.7)$ to $0.08(\mathrm{pH}=8)$ in case of ParticlesHP-CTAB and from 0.67 

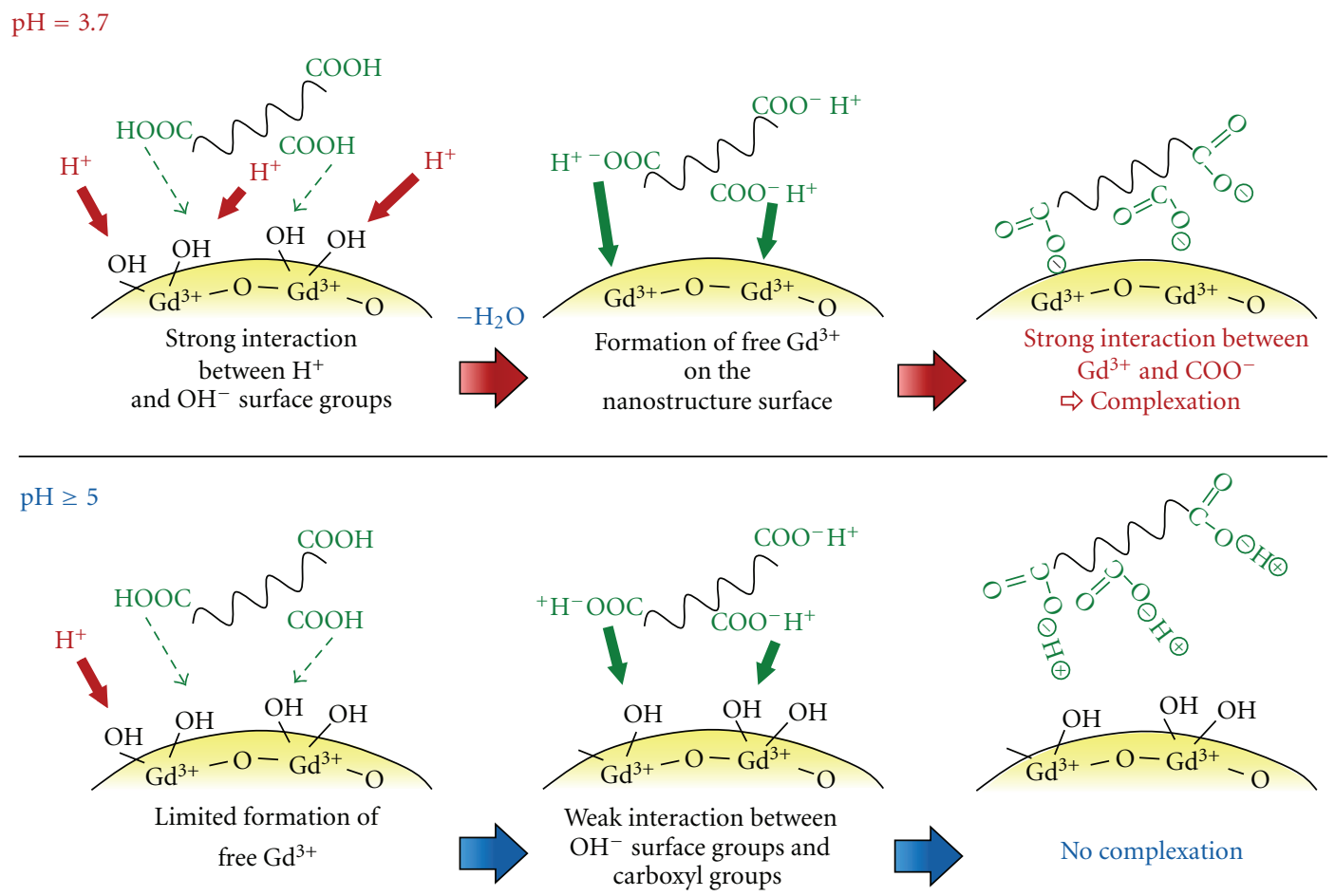

Scheme 2: Surface modification of $\mathrm{Gd}_{2} \mathrm{O}_{3}: \mathrm{Er}^{3+}, \mathrm{Yb}^{3+}$ with PEG- $b$-PAAc at low $(\sim 3.7)$ and increased $(\geq 5) \mathrm{pH}$ and the formation of a gadolinium-PEG-b-PAAc-complex.

TABLE 1: Mass loss $\left(\Delta m_{2}\right)$ and grafting rate $\left(\Delta m_{2} /\right.$ residual mass) determined by TG-DTA for PEG- $b$-PAAc modified ParticlesHP-CTAB and Rods 5 as a function of the modification $\mathrm{pH}$.

\begin{tabular}{lccccc}
\hline $\mathrm{pH}$ & \multicolumn{2}{c}{$\Delta m_{2}[\%]$} & \multicolumn{2}{c}{ Residual mass [\%] } & \multicolumn{2}{c}{ Grafting rate } \\
& Particles & Rods & Particles & Rods & Particles \\
\hline 3.7 & 22 & 33 & 72 & 49 & 0.31 \\
5.0 & 21 & 14 & 72 & 77 & 0.29 \\
6.5 & 14 & 14 & 82 & 82 & 0.18 \\
8.0 & 7 & 8 & 90 & 89 & 0.17 \\
\hline
\end{tabular}

$(\mathrm{pH}=3.7)$ to $0.09(\mathrm{pH}=8)$ in case of Rods5. Those data support the trend observed by FT-IR spectra, revealing that the surface modification is less pronounced when carried out at higher $\mathrm{pH}$. This observation can also be deduced to modification conditions approaching the isoelectric point of $\mathrm{Gd}_{2} \mathrm{O}_{3}: \mathrm{Er}^{3+}, \mathrm{Yb}^{3+}$ nanostructures as observed by $\zeta$-potential measurements $\left(p H_{(\zeta=0 \mathrm{mV})} \sim 8.5\right)$, which hinders the electrostatic adsorption of PEG- $b$-PAAc at high $\mathrm{pH}$.

Comparing the grafting rate at $\mathrm{pH} 3.7, \operatorname{Rods} 5$ exhibit a higher PEG- $b$-PAAc content than ParticlesHP-CTAB. However, the grafting rate of Rods5 drops significantly at a modification $\mathrm{pH} 5.0$ (grafting rate $\sim 0.18$ ). A similar drop is shifted to $\mathrm{pH} 6.5$ in case of ParticlesHP-CTAB (grafting rate $\sim 0.17$ ). This is in agreement with our observation in FTIR spectroscopy (Figure 5). Spectra recorded on ParticlesHP$C T A B$ modified at $\mathrm{pH} 5.0$ and 3.7 show the characteristic peak splitting for complex formation at 1419 and $1453 \mathrm{~cm}^{-1}$. On the other hand, the same peak splitting is shifted towards a modification $\mathrm{pH}$ of 3.7 in case of Rods5.
2.2.3. Chemical Durability. For applications of $\mathrm{Gd}_{2} \mathrm{O}_{3}$ : $\mathrm{Er}^{3+}, \mathrm{Yb}^{3+}$ nanostructures in biomedicine, protection from dissolution of $\mathrm{Gd}_{2} \mathrm{O}_{3}$ inducing the formation of toxic $\mathrm{Gd}^{3+}$ ions in acidic media (as found inside macrophages) is an essential task of the PEG- $b$-PAAc layer. Therefore, chemical durability of nanostructures modified at $\mathrm{pH} 3.7$ and 8 has been investigated, and the recorded graphs are presented in Figure 6.

Dissolution of lanthanide oxides in acidic solutions under $\mathrm{pH}$ less than 6.4 is well known. The $\mathrm{pH}$ of a suspension of lanthanide oxides reaches a saturation value of about 6.4 almost immediately after addition of the oxides into an acidic solution due to their dissolution [51]. Accordingly, $\mathrm{Gd}^{3+}$ ions start to be released from insufficiently coated $\mathrm{Gd}_{2} \mathrm{O}_{3}$ (modification $\mathrm{pH} 8$ ) resulting in an increase in $\mathrm{pH}$ reaching around 6 after 4 hrs. Results of FT-IR spectroscopy and TGDTA in dependence on modification $\mathrm{pH}$ revealed a higher PEG- $b$-PAAc content in case of modification $\mathrm{pH}$ 3.7. The slight increase in $\mathrm{pH}$ of the suspension of nanostructures 


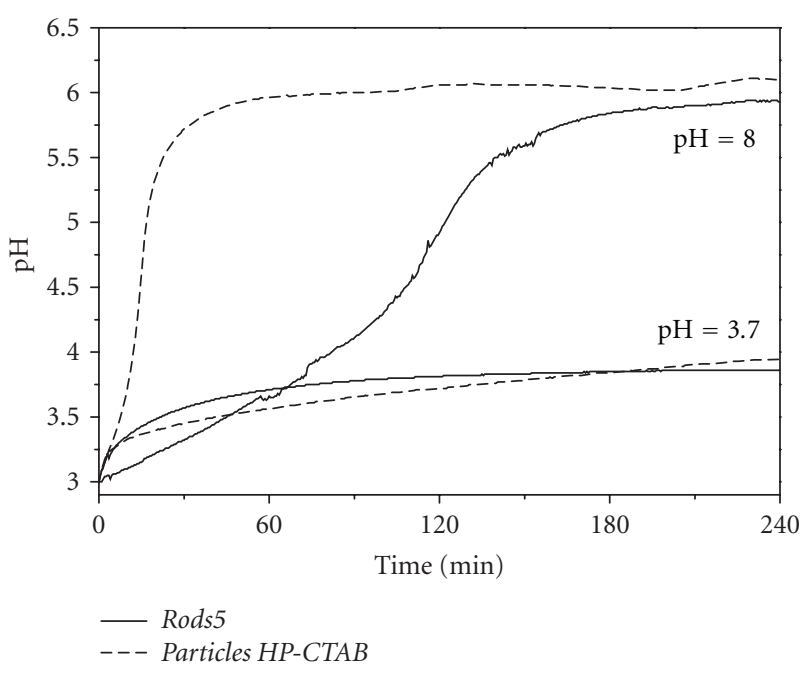

FIGURE 6: Influence of the modification $\mathrm{pH}$ on the chemical durability of PEG- $b$-PAAc modified $\mathrm{Gd}_{2} \mathrm{O}_{3}: \mathrm{Er}^{3+}, \mathrm{Yb}^{3+}$ under acidic conditions.

modified at $\mathrm{pH} 3.7$ indicates a starting dissolution of $\mathrm{Gd}_{2} \mathrm{O}_{3}$. However, the presence of sufficient polymer chains from surface modification enables the reaction between those free ions and the polymer chains $\left(\mathrm{COO}^{-}\right)$. As the released ions are trapped by the polymer and further dissolution is stopped, $\mathrm{pH}$ reaches a saturation value of around 3.9. In agreement with the formation of a complex between $\mathrm{Gd}^{3+}$ on the nanostructure surface and $\mathrm{COO}^{-}$in the PAAc chain at low modification $\mathrm{pH}$, nanostructures modified at $\mathrm{pH} 3.7$ show sufficient chemical durability, while the PEG- $b$-PAAc layer provided by modification at $\mathrm{pH} 8$ cannot fulfil acidic resistance requirements.

2.2.4. Size Distribution and Dispersion Stability in Aqueous Medium. The size distribution of bare and PEG- $b$-PAAc modified nanostructures dispersed in water is displayed in Figures $7(a)$ and $7(b)$. Bare nanostructures tend to aggregate to larger agglomerates of several $100 \mathrm{~nm}$ to micrometer size. On the other hand, data obtained for modified nanostructures suggest that PEG- $b$-PAAc modified nanostructures are well dispersed in aqueous solutions. The hydrodynamic mean diameters are 200 and $260 \mathrm{~nm}$ for ParticlesHP-CTAB modified at $\mathrm{pH} 3$ and 8 . Analogous diameters for Rods 5 are $170 \mathrm{~nm}(\mathrm{pH}=3)$ and $200 \mathrm{~nm}(\mathrm{pH}=8)$.

The capability of PEG- $b$-PAAc modification to avoid agglomeration of the nanostructures in aqueous media is also reflected in their dispersion stability. Dispersion stability of the nanostructures was investigated by adsorption measurements in a spectrophotometer. Results are presented in Figures 7(c) and 7(d). Accordingly, dispersion stability of ParticlesHP-CTAB in distilled water is improved by PEG- $b$-PAAc modification. In case of bare nanostructures, absorbance decreases linearly to around $85 \%$ within $2 \mathrm{hrs}$. In contrast, suspensions of PEG- $b$-PAAc modified ParticlesHP$C T A B$ and Rods5 remain stable with more than $90 \%$ absorbance after $2 \mathrm{hrs}$. The slightly concave decay of the curve recorded on ParticlesHP-CTAB modified at $\mathrm{pH} 3$ indicates even better stability than the convex shaped curve recorded for a modification $\mathrm{pH}$ of 8 . For Rods5, both modified samples exhibit a concave shaped curve indicating good dispersion stability.

With respect to potential biomedical applications we further investigated the dispersion stability of Particles HP-CTAB and Rods 5 without and with PEG- $b$-PAAc modification in an aqueous sodium chloride solution. Therefore, $1.5 \mathrm{~mL}$ of a $0.3 \mathrm{M} \mathrm{NaCl}$ solution were added to $2.5 \mathrm{~mL}$ of the nanostructure dispersion resulting in an overall saline concentration of $0.1 \mathrm{M}$. The increase in solution ionic strength is expected to increase the hydrodynamic diameter of the dispersed nanostructures, resulting in unstable, highly agglomerated dispersions [52]. Thus, as obvious from Figures 7(e) and $7(\mathrm{f})$, the increase of the ionic strength results in immediate aggregation of the dispersed (unmodified) nanostructures. However, surface modification with PEG- $b$-PAAc effectively improves the dispersion stability (blue and red graphs) and suppresses agglomeration under such conditions.

Figure 8 summarizes the relationship between modification $\mathrm{pH}$ and physicochemical properties of PEG- $b$-PAAc modified ParticlesHP-CTAB and Rods5. There is a clear trend of enhanced surface modification with decreasing $\mathrm{pH}$ indicated by an increase in grafting rate determined from TG graphs and an increased $\mathrm{COO}^{-}$peak area in FT-IR spectra. Further, FT-IR data suggest the formation of a gadolinium-PEG-b-PAAc-complex in case of modification under acidic conditions $(\mathrm{pH}<5)$. With regard to biomedical applications, acidic durability of nanostructures is improved by modification at low $\mathrm{pH}$, which is evident from the lack of increase in $\mathrm{pH}$ during the chemical durability test.

\section{Conclusions}

Erbium and ytterbium doped gadolinium oxide $\left(\mathrm{Gd}_{2} \mathrm{O}_{3}\right.$ : $\left.\mathrm{Er}^{3+}, \mathrm{Yb}^{3+}\right)$ spherical as well as rod-like nanostructures have been synthesized by precipitation methods and hydrothermal treatment. Variation of the precipitation conditions allows the control of aspect ratio and particle size ranging from 5 to 18 , respectively, $40 \mathrm{~nm}$ to micrometer range. The poor chemical durability of gadolinium oxide under acidic conditions induces cell death when incubated with macrophages, which must be overcome prior to applications in biomedicine. Surface modification with PEG- $b$ PAAc provides a protecting layer. Herein, variation of the modification $\mathrm{pH}$ takes strong influence on grafting rate and bonding characteristics between the $\mathrm{Gd}_{2} \mathrm{O}_{3}$ surface and the PEG- $b$-PAAc layer as observed by TG-DTA analysis and FT-IR spectroscopy. It was shown that a modification $\mathrm{pH}$ in the acidic range results in higher grafting rate when compared to basic modification conditions. The formation of a gadolinium-PEG-complex between $\mathrm{Gd}^{3+}$ on the nanostructure surface and $\mathrm{COO}^{-}$groups in the PAAc chain in case of low modification $\mathrm{pH}$ improves the surface properties such as acidic durability and dispersion stability of the nanostructures. Further, the obtained acidic durability ensures the reduced release of toxic $\mathrm{Gd}^{3+}$ ions providing 


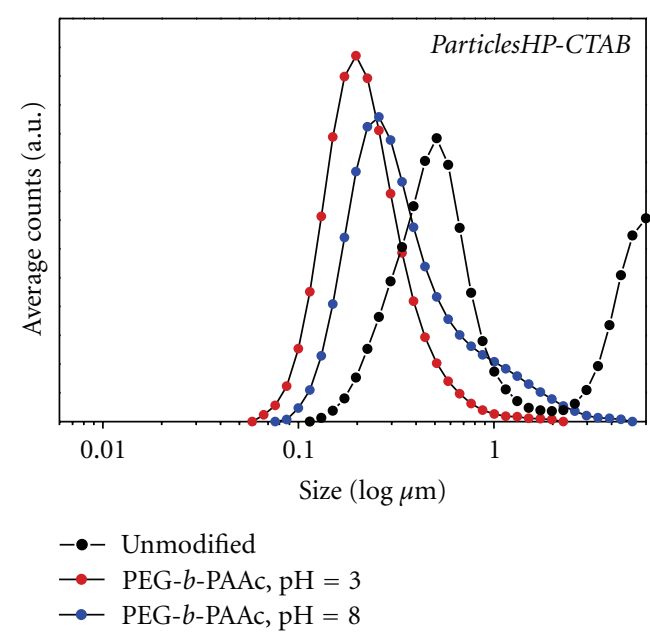

(a)

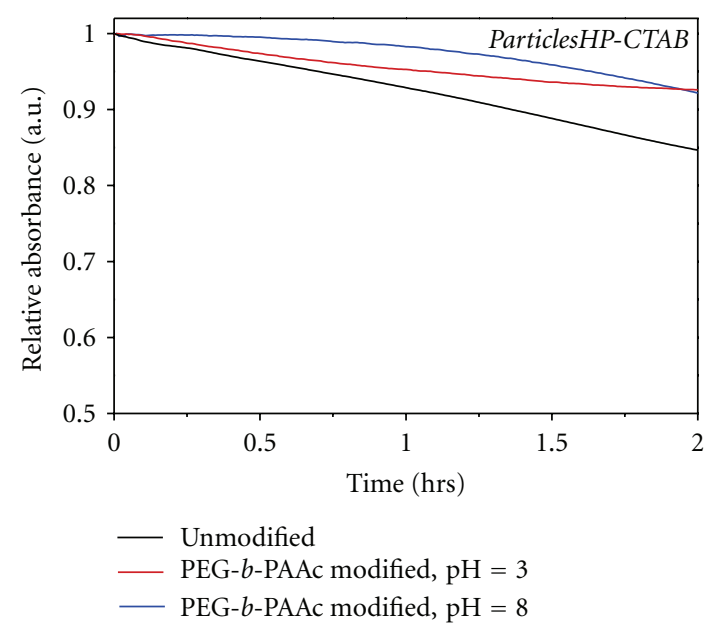

(c)

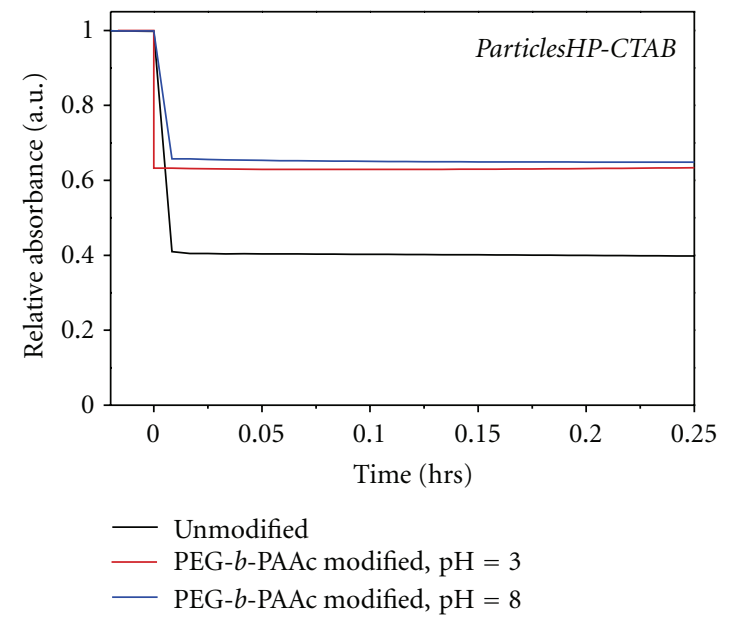

(e)

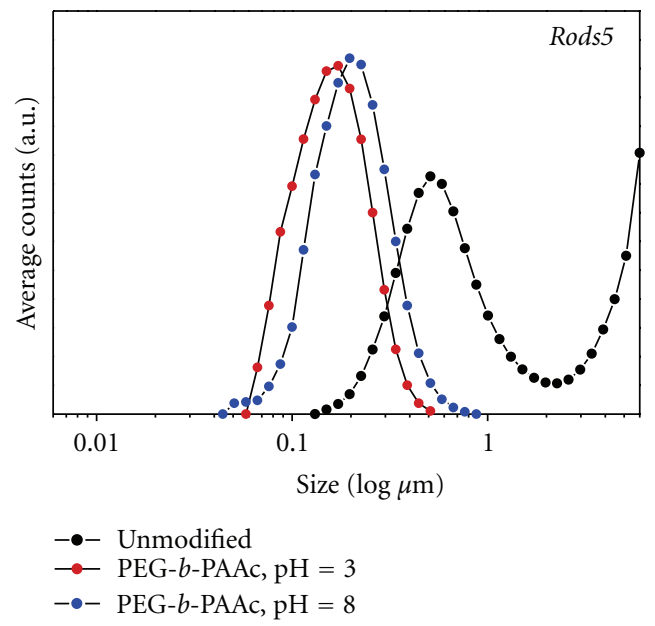

(b)

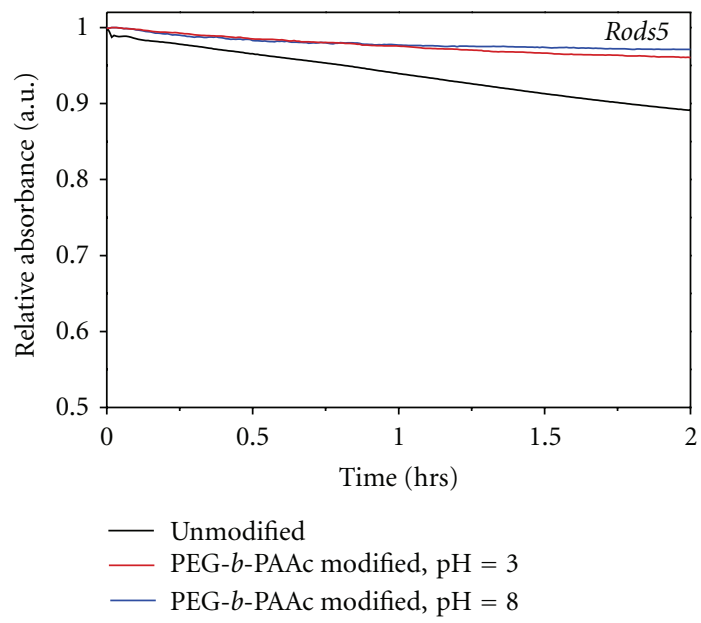

(d)

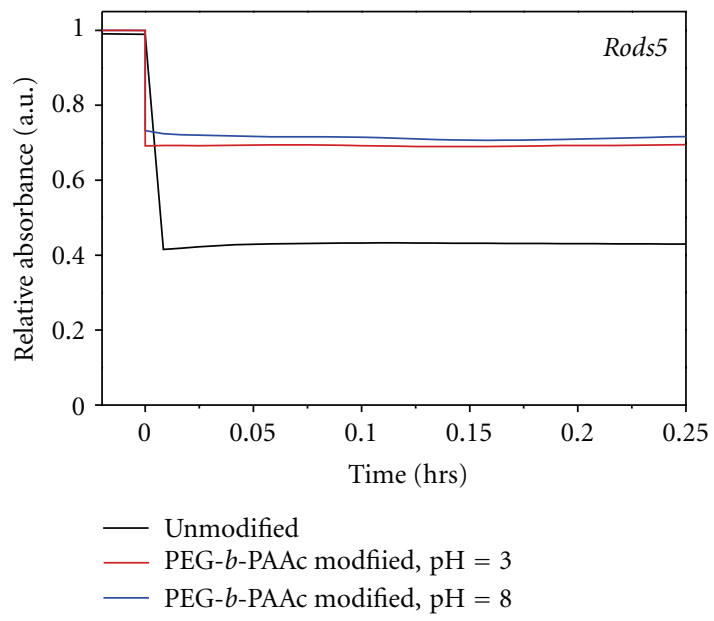

(f)

FIgURE 7: Influence of PEG-b-PAAc modification on (a), (b) the hydrodynamic diameter distribution, (c), (d) dispersion stability of ParticlesHP-CTAB and Rods5 in pure water and (e), (f) at increased solution ionic strength $(0.1 \mathrm{M} \mathrm{NaCl})$. 


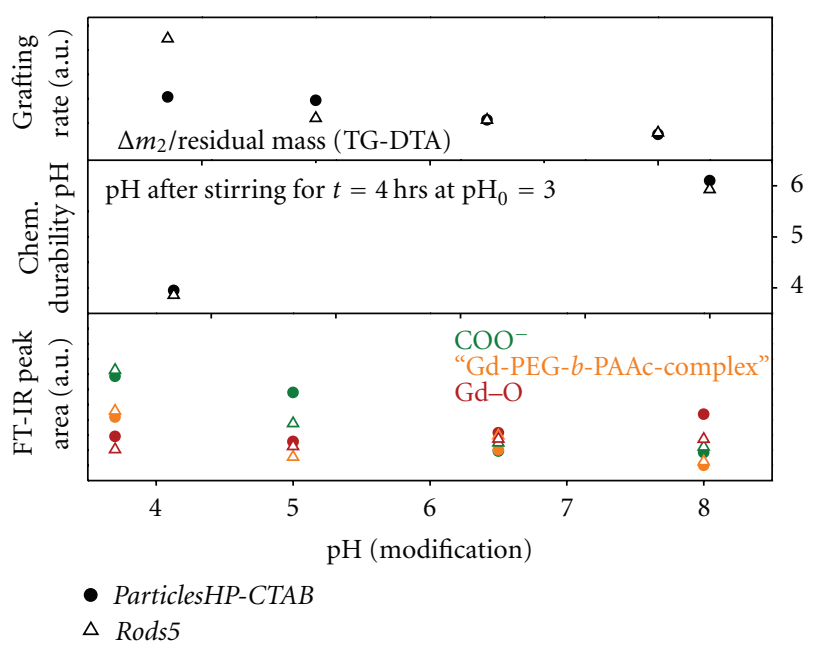

FIgure 8: Trends in physico-chemical properties of PEG- $b$-PAAc modified ParticlesHP-CTAB and Rods5 as a function of modification $\mathrm{pH}$.

good biocompatibility and making the investigated system a promising candidate for future bioimaging applications.

\section{Experimental Section}

4.1. Material Synthesis. Starting materials like lanthanide nitrates $(\mathrm{Ln}=\mathrm{Gd}, \mathrm{Er}, \mathrm{Yb})$, urea, urease enzyme, PEG-6000 (poly(ethylene glycol), Mw = 6000), CTAB (cetyltrimethylammonium bromide), $\mathrm{KOH}$ (potassium hydroxide), ammonia (25 wt $\%$ aqueous solution), $\mathrm{Na}_{2} \mathrm{CO}_{3}$ (sodium carbonate), and PEG-b-PAAc (poly(ethylene glycol)-b-poly(acrylic acid) block copolymer, $\mathrm{Mw}=5000 / 3200)$ were purchased from usual commercial sources and were used without further purification.

For the alkaline precipitation, $1.81 \mathrm{~g}$ ( $4 \mathrm{mmol})$ $\mathrm{Gd}\left(\mathrm{NO}_{3}\right)_{3} 6 \mathrm{H}_{2} \mathrm{O}$ were dissolved in $100 \mathrm{~mL}$ distilled water. To obtain $\mathrm{Gd}_{2} \mathrm{O}_{3}$ particles doped with $1 \mathrm{~mol} \%$ of $\mathrm{Er}^{3+}$ and $\mathrm{Yb}^{3+} 18.2 \mathrm{mg}(0.041 \mathrm{mmol}) \operatorname{Er}\left(\mathrm{NO}_{3}\right)_{3} 5 \mathrm{H}_{2} \mathrm{O}$ and $14.7 \mathrm{mg}$ (approx. $0.041 \mathrm{mmol}) \mathrm{Yb}\left(\mathrm{NO}_{3}\right)_{3} x \mathrm{H}_{2} \mathrm{O}$ were added to the gadolinium nitrate solution. An aqueous $\mathrm{Na}_{2} \mathrm{CO}_{3}$ solution ( $c=0.5 \mathrm{~mol} / \mathrm{L}, V=100 \mathrm{~mL}$ ) was added to the lanthanide nitrate solution and stirred at room temperature for $2 \mathrm{hrs}$. For the homogeneous precipitation, $758.3 \mathrm{mg}(1.68 \mathrm{mmol})$ $\mathrm{Gd}\left(\mathrm{NO}_{3}\right)_{3} 6 \mathrm{H}_{2} \mathrm{O}$ and $1 \mathrm{~mol} \% \quad \operatorname{Er}\left(\mathrm{NO}_{3}\right)_{3} 5 \mathrm{H}_{2} \mathrm{O} \quad(7.5 \mathrm{mg}$, $0.017 \mathrm{mmol})$, respectively, $1 \mathrm{~mol} \% \mathrm{Yb}\left(\mathrm{NO}_{3}\right)_{3} \times \mathrm{H}_{2} \mathrm{O}(6.1 \mathrm{mg}$, approx. $0.017 \mathrm{mmol}$ ) were dissolved in $300 \mathrm{~mL} \mathrm{H}_{2} \mathrm{O}$. Additionally, as a surfactant either $30 \mathrm{~g}$ ( $5 \mathrm{mmol})$ PEG-6000 or 1-10 mmol CTAB were added, followed by stirring for $50 \mathrm{~min}$ at room temperature. $9.01 \mathrm{~g}(150 \mathrm{mmol})$ urea was added to the pure Ln- or Ln-surfactant-solution and the mixture was kept stirring for $10 \mathrm{~min}$. For precipitation, the mixture was stirred at $85^{\circ} \mathrm{C}$ for $30 \mathrm{~min}$. In case of the enzymatic precipitation $1.35 \mathrm{~g}(3 \mathrm{mmol}) \mathrm{Gd}\left(\mathrm{NO}_{3}\right)_{3} 6 \mathrm{H}_{2} \mathrm{O}$ and $1 \mathrm{~mol} \% \quad \mathrm{Er}\left(\mathrm{NO}_{3}\right)_{3} 5 \mathrm{H}_{2} \mathrm{O} \quad(13.4 \mathrm{mg}, \quad 0.030 \mathrm{mmol})$, respectively, $1 \mathrm{~mol} \% \quad \mathrm{Yb}\left(\mathrm{NO}_{3}\right)_{3} \times \mathrm{H}_{2} \mathrm{O} \quad(10.9 \mathrm{mg}$, approx. $0.030 \mathrm{mmol}$ ) were dissolved in $200 \mathrm{~mL} \mathrm{H}_{2} \mathrm{O}$ and $18.02 \mathrm{~g}$ $(300 \mathrm{mmol})$ urea were added. This solution was added to an aqueous urease enzyme solution (22.5 $\mathrm{mg}$ urease enzyme in $100 \mathrm{~mL} \mathrm{H}_{2} \mathrm{O}$ ) to initiate precipitation. The mixture was stirred at room temperature for $2 \mathrm{hrs}$. In the hydrothermal synthesis, the concentration of gadolinium nitrate was set to $0.05 \mathrm{~mol} / \mathrm{L}$ at a total volume of $30 \mathrm{~mL}$. Therefore, in a first approach $677 \mathrm{mg}(1.5 \mathrm{mmol})$ $\mathrm{Gd}\left(\mathrm{NO}_{3}\right)_{3} 6 \mathrm{H}_{2} \mathrm{O}$ and $6.8 \mathrm{mg}(0.015 \mathrm{mmol}) \mathrm{Er}\left(\mathrm{NO}_{3}\right)_{3} 5 \mathrm{H}_{2} \mathrm{O}$ and $5.5 \mathrm{mg}$ (approx. $0.015 \mathrm{mmol}$ ) $\mathrm{Yb}\left(\mathrm{NO}_{3}\right)_{3} x \mathrm{H}_{2} \mathrm{O}$ were dissolved in $25.5 \mathrm{~mL} \mathrm{H}_{2} \mathrm{O}$. The obtained solution was transferred into teflon liners $(V=50 \mathrm{~mL})$ and activated with $4.5 \mathrm{~mL} 1 \mathrm{M}$ aqueous $\mathrm{KOH}$ solution. In a second approach, $677 \mathrm{mg}(1.5 \mathrm{mmol}) \quad \mathrm{Gd}\left(\mathrm{NO}_{3}\right)_{3} 6 \mathrm{H}_{2} \mathrm{O}$ and $6.8 \mathrm{mg} \quad(0.015 \mathrm{mmol}) \quad \mathrm{Er}\left(\mathrm{NO}_{3}\right)_{3} 5 \mathrm{H}_{2} \mathrm{O} \quad$ and $5.5 \mathrm{mg}$ (approx. $\quad 0.015 \mathrm{mmol}) \quad \mathrm{Yb}\left(\mathrm{NO}_{3}\right)_{3} x \mathrm{H}_{2} \mathrm{O}$ were dissolved in $(30-y) \mathrm{mL} \mathrm{H}_{2} \mathrm{O}(y=0.1,0.2,0.35,0.5,1.0,2.0,3.0$, and $5.0 \mathrm{~mL}$ ) and the mixture was activated by addition of $z \mathrm{~mL}(z=0.1,0.2,0.35,0.5,1.0,2.0,3.0$, and $5.0 \mathrm{~mL})$ of aqueous ammonia hydroxide $(25 \mathrm{wt} \%)$ resulting in solutions with a $\mathrm{pH}$ value of $6.6,6.8,7.1,8.7,9.2,10.3$, 10.3 and 10.9. Alternatively, the lanthanide nitrates were dissolved in $9 \mathrm{~mL} \mathrm{H}_{2} \mathrm{O}$ and quickly added to an aqueous ammonia solution ( $1 \mathrm{~mL} 25$ wt\% ammonia solution $+20 \mathrm{~mL} \mathrm{H}_{2} \mathrm{O}$ ) under rigorous stirring. After enclosing the teflon liners in steel autoclaves, the autoclaves were placed in a furnace, respectively, wrapped into a heating mantle system (equipped with a thermocouple K:Class:2 by Toho and a program temperature controller TXN700 by AS ONE) and heated to a temperature of $200^{\circ} \mathrm{C}$ that was kept for 6 to $12 \mathrm{hrs}$. The obtained powders were collected by centrifugation, washed two times with distilled water, and dried at $80^{\circ} \mathrm{C}$ for at least $12 \mathrm{hrs}$. Crystalline oxide powders were obtained by postthermal treatment at $900^{\circ} \mathrm{C}$ (30 $\mathrm{min})$.

4.2. Surface Modification. For surface modification with PEG- $b$-PAAc, $\mathrm{Gd}_{2} \mathrm{O}_{3}: \mathrm{Er}^{3+}, \mathrm{Yb}^{3+}$ nanostructures were dispersed in water $(c=2 \mathrm{mg} / \mathrm{mL})$ and sonicated for $30 \mathrm{~min}$ at room temperature. An aqueous PEG- $b$-PAAc solution was added into the nanostructure dispersion, resulting in final concentrations of $0.6 \mathrm{mg} / \mathrm{mL} \mathrm{Gd}_{2} \mathrm{O}_{3}: \mathrm{Er}^{3+}, \mathrm{Yb}^{3+}$ and $1.2 \mathrm{mg} / \mathrm{mL}$ PEG- $b$-PAAc. The mixtures were stirred at $35^{\circ} \mathrm{C}$ for $24 \mathrm{hrs}$. In order to investigate the influence of $\mathrm{pH}$ during modification process, the $\mathrm{pH}$ of the initial aqueous PEG- $b$-PAAc solution $(\mathrm{pH}=3.7)$ was adjusted by addition of $\mathrm{NaOH}$ to values of approximately 5.0, 6.5, and 8.0 before adding the mixture into the nanostructure dispersion, followed by stirring for $24 \mathrm{hrs}$ at $35^{\circ} \mathrm{C}$. The obtained surface modified powders were collected by centrifugation, washed at least three times with distilled water, and dried at room temperature. For the investigation of the dispersion stability and for dynamic light scattering (DLS) measurements, PEG6000 assisted modification with PEG- $b$-PAAc was achieved at $\mathrm{pH} 3.0$ and 8.0. Therefore, PEG-6000 was added to the $\mathrm{Gd}_{2} \mathrm{O}_{3}: \mathrm{Er}^{3+}, \mathrm{Yb}^{3+}$ suspension and sonicated for $10 \mathrm{~min}$ prior to the addition of the PEG- $b$-PAAc solution $(\mathrm{pH}=3.0$ or 8.0). The final concentrations of PEG-6000 and PEG- $b$ PAAc were both $0.6 \mathrm{mg} / \mathrm{mL}$. The obtained surface modified 
powders were collected by centrifugation, washed at least three times with distilled water, and redispersed into distilled water without further drying.

4.3. Material Characterization. The crystalline phase of the samples was determined by powder XRD with a ULTIMA III diffractometer (Rigaku) using $\mathrm{CuK} \alpha$ radiation. Crystal sizes were determined by Scherrer equation $d=K \lambda /(\mathrm{FWMH}$ $\cos (\theta))$ with $K=0.9$ and $\lambda=0.154 \mathrm{~nm}$. Morphology of the obtained powders was investigated by scanning electron microscope (S-4200, Hitachi). For FT-IR spectroscopy, samples were mixed with $\mathrm{KBr}$ and spectra of the powders were recorded under vacuum conditions using a JASCO FT/IR-6500 spectrometer. TG-DTA graphs were recorded by use of DTG-60 Simultaneous DTA-TG apparatus with FC-60A gas flow controller by Shimadzu with a heating rate of $10 \mathrm{~K} / \mathrm{min}$ and an air flow of $50 \mathrm{~mL} / \mathrm{min}$. Surface charge of the nanostructures was determined with a Delsa Nano Submicron Particle Size and Zeta Potential analyzer by Beckman Coulter using the disposable cell for zeta potential unit. Nanostructures were suspended $(c=0.67 \mathrm{mg} / \mathrm{mL})$ in either distilled water $(\mathrm{pH}=5.2)$ or an aqueous $\mathrm{NaOH}$ solution with an adjusted $\mathrm{pH}$ in the range 5 to 12 . Zetapotential was calculated from the mobility by the equipment's software using the Smoluchowski model. In order to investigate chemical durability under acidic conditions as-prepared or PEG-modified nanostructures were added into an aqueous $\mathrm{HCl}$ solution with an initial $\mathrm{pH}$ of 3 $\left(c\left(\mathrm{Gd}_{2} \mathrm{O}_{3}: \mathrm{Er}^{3+}, \mathrm{Yb}^{3+}\right)=0.2 \mathrm{mg} / \mathrm{mL}\right)$. Under rigorous stirring, the time-dependent change of $\mathrm{pH}$ was recorded by use of an Auto Titrator Com-1600 (Hiramura). Dispersion stability of an aqueous suspension of bare and modified (PEG6000 assisted modification) $\mathrm{Gd}_{2} \mathrm{O}_{3}: \mathrm{Er}^{3+}, \mathrm{Yb}^{3+}$ nanostructures was investigated by absorbance measurements with a V-630 Spectrophotometer by JASCO. The size distribution of PEG$b$-PAAc modified powders (PEG-6000 assisted modification) in distilled water was measured by DLS using a Dynamic Light Scattering Particle Size Analyzer LB-550 by Horiba.

\section{Acknowledgment}

The authors thank Dr. Lionel Vayssieres (WPI Center for Materials NanoArchitectonics (MANA), National Institute for Materials Science (NIMS), Tsukuba, Japan) for scientific discussion and provision of the zeta-potential equipment.

\section{References}

[1] P. Sharma, S. Brown, G. Walter, S. Santra, and B. Moudgil, "Nanoparticles for bioimaging," Advances in Colloid and Interface Science, vol. 123-126, pp. 471-485, 2006.

[2] S. A. Hilderbrand, F. Shao, C. Salthouse, U. Mahmood, and R. Weissleder, "Upconverting luminescent nanomaterials: application to in vivo bioimaging," Chemical Communications, no. 28, pp. 4188-4190, 2009.

[3] G. K. Das and T. T. Y. Tan, "Rare-earth-doped and codoped $\mathrm{y}_{2} \mathrm{O}_{3}$ nanomaterials as potential bioimaging probes," Journal of Physical Chemistry C, vol. 112, no. 30, pp. 11211-11217, 2008.
[4] P. R. Diamente and F. C. J. M. van Veggel, "Water-soluble $\mathrm{Ln}^{3+}$ doped $\mathrm{LaF}_{3}$ nanoparticles: retention of strong luminescence and potential as biolabels," Journal of Fluorescence, vol. 15, no. 4, pp. 543-551, 2005.

[5] J.-C. Boyer, M.-P. Manseau, J. I. Murray, and F. C. J. M. Van Veggel, "Surface modification of upconverting $\mathrm{NaYF}_{4}$ nanoparticles with PEG-phosphate ligands for NIR $(800 \mathrm{~nm})$ biolabeling within the biological window," Langmuir, vol. 26, no. 2, pp. 1157-1164, 2010.

[6] K. Soga, K. Tokuzen, K. Tsuji, T. Yamano, H. Hyodo, and H. Kishimoto, "NIR bioimaging: development of liposomeencapsulated, rare-earth-doped $\mathrm{y}_{2} \mathrm{O}_{3}$ nanoparticles as fluorescent probes," European Journal of Inorganic Chemistry, no. 18, pp. 2673-2677, 2010.

[7] Z. Y. Ma, D. Dosev, M. Nichkova, S. J. Gee, B. D. Hammock, and I. M. Kennedy, "Synthesis and bio-functionalization of multifunctional magnetic $\mathrm{Fe}_{3} \mathrm{O}_{4} @ \mathrm{Y}_{2} \mathrm{O}_{3}$ :Eu nanocomposites," Journal of Materials Chemistry, vol. 19, no. 27, pp. 4695-4700, 2009.

[8] J.-L. Bridot, A.-C. Faure, S. Laurent et al., "Hybrid gadolinium oxide nanoparticles: multimodal contrast agents for in vivo imaging," Journal of the American Chemical Society, vol. 129, no. 16, pp. 5076-5084, 2007.

[9] Y. I. Park, J. H. Kim, K. T. Lee et al., "Nonblinking and nonbleaching upconverting nanoparticles as an optical imaging nanoprobe and T1 magnetic resonance imaging contrast agent," Advanced Materials, vol. 21, no. 44, pp. 4467-4471, 2009.

[10] G. K. Das, B.-C. Heng, S. C. Ng et al., "Gadolinium oxide ultranarrow nanorods as multimodal contrast agents for optical and magnetic resonance imaging," Langmuir, vol. 26, no. 11, pp. 8959-8965, 2010.

[11] S. Mandal, S. Phadtare, and M. Sastry, "Interfacing biology with nanoparticles," Current Applied Physics, vol. 5, no. 2, pp. 118-127, 2005.

[12] F. Söderlind, H. Pedersen Jr., R. M. Petoral, P.-O. Käll, and K. Uvdal, "Synthesis and characterisation of $\mathrm{Gd}_{2} \mathrm{O}_{3}$ nanocrystals functionalised by organic acids," Journal of Colloid and Interface Science, vol. 288, no. 1, pp. 140-148, 2005.

[13] A. Hoshino, N. Manabe, K. Fujioka, K. Suzuki, M. Yasuhara, and K. Yamamoto, "Use of fluorescent quantum dot bioconjugates for cellular imaging of immune cells, cell organelle labeling, and nanomedicine: surface modification regulates biological function, including cytotoxicity," Journal of Artificial Organs, vol. 10, no. 3, pp. 149-157, 2007.

[14] S. T. Selvan, T. T. Y. Tan, D. K. Yi, and N. R. Jana, "Functional and multifunctional nanoparticles for bioimaging and biosensing," Langmuir, vol. 26, no. 14, pp. 11631-11641, 2010.

[15] M. R. Karim and J. H. Yeum, "Poly(vinyl alcohol) $-\mathrm{Fe}_{3} \mathrm{O}_{4}$ nanocomposites prepared by the electrospinning technique," Soft Materials, vol. 8, no. 3, pp. 197-206, 2010.

[16] L. E. van Vlerken, T. K. Vyas, and M. M. Amiji, "Poly(ethylene glycol)-modified nanocarriers for tumor-targeted and intracellular delivery," Pharmaceutical Research, vol. 24, no. 8, pp. 1405-1414, 2007.

[17] E.-C. Kang, A. Ogura, K. Kataoka, and Y. Nagasaki, "Preparation of water-soluble PEGylated semiconductor nanocrystals," Chemistry Letters, vol. 33, no. 7, pp. 840-841, 2004.

[18] T. Niidome, M. Yamagata, Y. Okamoto et al., "PEG-modified gold nanorods with a stealth character for in vivo applications," Journal of Controlled Release, vol. 114, no. 3, pp. 343347, 2006.

[19] E. Oh, K. Susumu, R. Goswami, and H. Mattoussi, "One-phase synthesis of water-soluble gold nanoparticles with control over 
size and surface functionalities," Langmuir, vol. 26, no. 10, pp. 7604-7613, 2010.

[20] C. Barrera, A. P. Herrera, and C. Rinaldi, "Colloidal dispersions of monodisperse magnetite nanoparticles modified with poly(ethylene glycol)," Journal of Colloid and Interface Science, vol. 329, no. 1, pp. 107-113, 2009.

[21] V. Cauda, A. Schlossbauer, and T. Bein, "Bio-degradation study of colloidal mesoporous silica nanoparticles: effect of surface functionalization with organo-silanes and poly(ethylene glycol)," Microporous and Mesoporous Materials, vol. 132, no. 1-2, pp. 60-71, 2010.

[22] M. Kamimura, D. Miyamoto, Y. Saito, K. Soga, and Y. Nagasaki, "Design of poly(ethylene glycol)/streptavidin coimmobilized upconversion nanophosphors and their application to fluorescence biolabeling," Langmuir, vol. 24, no. 16, pp. 8864-8870, 2008.

[23] E. Hemmer, T. Yamanao, H. Kishimoto, and K. Soga, "Gadolinium-containing inorganic nanostructures for biomedical applications: cytotoxic aspects," in Proceedings of the International Conference on Nanoscience and Nanotechnology (ICONN '10), pp. 225-229, Sydney, Australia, 2010.

[24] E. Hemmer, T. Yamano, H. Kishimoto, and K. Soga, "Cytotoxic aspects of gadolinium oxidenanostructures," submitted to. Acta Biomaterialia.

[25] X. Wang and Y. Li, "Rare-earth-compound nanowires, nanotubes, and fullerene-like nanoparticles: synthesis, characterization, and properties," Chemistry, vol. 9, no. 22, pp. 56275635, 2003.

[26] J. Yang, C. Li, Z. Cheng et al., "Size-tailored synthesis and luminescent properties of one-dimensional $\mathrm{Gd}_{2} \mathrm{O}_{3}: \mathrm{Eu}^{3+}$ nanorods and microrods," Journal of Physical Chemistry C, vol. 111, no. 49, pp. 18148-18154, 2007.

[27] N. Zhang, R. Yi, L. Zhou et al., "Lanthanide hydroxide nanorods and their thermal decomposition to lanthanide oxide nanorods," Materials Chemistry and Physics, vol. 114, no. 1, pp. 160-167, 2009.

[28] E. Hemmer, H. Takeshita, T. Yamano et al., "In-vitro and in-vivo investigations of upconversion and NIR emitting $\mathrm{Gd}_{2} \mathrm{O}_{3}: \mathrm{Er}^{3+}, \mathrm{Yb}^{3+}$ nanostructures for Biomedical Applications," Journal of Materials Science: Materials in Medicine. In press.

[29] N. Venkatachalam, Y. Saito, and K. Soga, "Synthesis of $\mathrm{Er}^{3+}$ doped $\mathrm{Y}_{2} \mathrm{O}_{3}$ nanophosphors," Journal of the American Ceramic Society, vol. 92, no. 5, pp. 1006-1010, 2009.

[30] E. Matijević and W. P. Hsu, "Preparation and properties of monodispersed colloidal particles of lanthanide compounds. I. Gadolinium, europium, terbium, samarium, and cerium(III)," Journal of Colloid And Interface Science, vol. 118, no. 2, pp. 506-523, 1987.

[31] I. Y. Park, D. Kim, J. Lee, S. H. Lee, and K.-J. Kim, "Effects of urea concentration and reaction temperature on morphology of gadolinium compounds prepared by homogeneous precipitation," Materials Chemistry and Physics, vol. 106, no. 1, pp. 149-157, 2007.

[32] W. Zhu, J. Ma, L. Xu, W. Zhang, and Y. Chen, "Controlled synthesis of $\mathrm{Nd}(\mathrm{OH})_{3}$ and $\mathrm{Nd}_{2} \mathrm{O}_{3}$ nanoparticles by microemulsion method," Materials Chemistry and Physics, vol. 122, no. 2-3, pp. 362-367, 2010.

[33] J. Yue, X. Jiang, Q. Zeng, and A. Yu, "Experimental and numerical study of cetyltrimethylammonium bromide (CTAB)directed synthesis of goethite nanorods," Solid State Sciences, vol. 12, no. 7, pp. 1152-1159, 2010.

[34] M. Pourbaix, Atlas of Electrochemical Equilibria in Aqueous Solutions, Association of Corrosion Engineers, Cebelcor,
Houston, Tex, USA, 2nd edition, 1974.

[35] G. Du and G. Van Tendeloo, "Preparation and structure analysis of $\mathrm{Gd}(\mathrm{OH})_{3}$ nanorods," Nanotechnology, vol. 16, no. 4, pp. 595-597, 2005.

[36] X. Wang and Y. Li, "Synthesis and characterization of lanthanide hydroxide single-crystal nanowires," Angewandte Chemie, vol. 41, no. 24, pp. 4790-4793, 2002.

[37] X. Wang and Y. Li, "Solution-based routes to transition-metal oxide one-dimensional nanostructures," Pure and Applied Chemistry, vol. 78, no. 1, pp. 45-64, 2006.

[38] L. Ma, W. X. Chen, J. Zhao, and Y.-F. Zheng, "Synthesis of $\operatorname{Pr}(\mathrm{OH})_{3}$ and $\operatorname{Pr}_{6} \mathrm{O}_{11}$ nanorods by microwave-assisted method: effects of concentration of alkali and microwave heating time," Journal of Crystal Growth, vol. 303, no. 2, pp. 590-596, 2007.

[39] K. Soga, K. Tokuzen, K. Tsuji et al., "Application of ceramic phosphors for near infrared biomedical imaging technologies," in Proceedings of the Optical Components and Materials VII, vol. 7598 of Proceedings of SPIE, pp. 759807-1-759807-9, January 2010.

[40] D. Qilin, S. Hongwei, W. Meiyuan et al., "Size and concentration effects on the photoluminescence of $\mathrm{La}_{2} \mathrm{O}_{2} \mathrm{~S}: \mathrm{Eu}^{3+}$ nanocrystals," Journal of Physical Chemistry C, vol. 112, no. 49, pp. 19399-19404, 2008.

[41] E. Ma, Z. Hu, Y. Wang, and F. Bao, "Influence of structural evolution on fluorescence properties of transparent glass ceramics containing $\mathrm{LaF}_{3}$ nanocrystals," Journal of Luminescence, vol. 118, no. 2, pp. 131-138, 2006.

[42] H. Schäfer, P. Ptacek, B. Voss, H. Eickmeier, J. Nordmann, and M. Haase, "Synthesis and characterization of upconversion fluorescent $\mathrm{yb}^{3+}, \mathrm{er}^{3+}$ doped $\mathrm{rby}_{2} \mathrm{f}_{7}$ nano-and microcrystals," Crystal Growth and Design, vol. 10, no. 5, pp. 2202-2208, 2010.

[43] A. Pohl and G. Westin, "Alkoxide route to $\mathrm{La} 0.5 \mathrm{Sr} 0.5 \mathrm{CoO} 3$ films and powders," Journal of the American Ceramic Society, vol. 88, no. 8, pp. 2099-2105, 2005.

[44] R. Weber, S. Hampton, P. C. Nordine, T. Key, and R. Scheunemann, "Er ${ }^{3+}$ fluorescence in rare-earth aluminate glass," Journal of Applied Physics, vol. 98, no. 4, Article ID 043521, 9 pages, 2005.

[45] A. Pohl, G. Westin, and K. Jansson, "Preparation of $\mathrm{La}_{0.67} \mathrm{Ca}_{0.33} \mathrm{MnO}_{3}$ nanophase powders and films from alkoxide precursors," Chemistry of Materials, vol. 14, no. 5, pp. 19811988, 2002.

[46] B. Feng, R. Y. Hong, L. S. Wang et al., "Synthesis of $\mathrm{Fe}_{3} \mathrm{O}_{4}$ / APTES/PEG diacid functionalized magnetic nanoparticles for MR imaging," Colloids and Surfaces A, vol. 328, no. 1-3, pp. 52-59, 2008

[47] H. Kaczmarek and A. Szalla, "Photochemical transformation in poly(acrylic acid)/poly(ethylene oxide) complexes," Journal of Photochemistry and Photobiology A, vol. 180, no. 1-2, pp. 46-53, 2006.

[48] N. Kato, P. Schuetz, A. Fery, and F. Caruso, "Thin multilayer films of weak polyelectrolytes on colloid particles," Macromolecules, vol. 35, no. 26, pp. 9780-9787, 2002.

[49] J. R. Allan, B. McCloy, and A. R. Gardner, "The preparation and characterisation of a complex of copper with poly(acrylic acid) and an assessment of its suitability as an anti-static additive for polyethylene," Thermochimica Acta, vol. 214, no. 2, pp. 249-253, 1993.

[50] J. Kuang, J. Yuan, M. Zhou, W. Yuan, X. Sui, and Z. Li, "Grafting of PEG onto lanthanum hydroxide nanowires," 
Materials Letters, vol. 62, no. 25, pp. 4078-4080, 2008.

[51] H. Hyodo, N. Sato, K. Kitano, and K. Soga, "Surface modification of ceramic nanophosphors by atmospheric pressure plasma," Journal of Photopolymer Science and Technology, vol. 24, no. 4, pp. 429-433, 2011.

[52] J. Jiang, G. Oberdörster, and P. Biswas, "Characterization of size, surface charge, and agglomeration state of nanoparticle dispersions for toxicological studies," Journal of Nanoparticle Research, vol. 11, no. 1, pp. 77-89, 2009. 

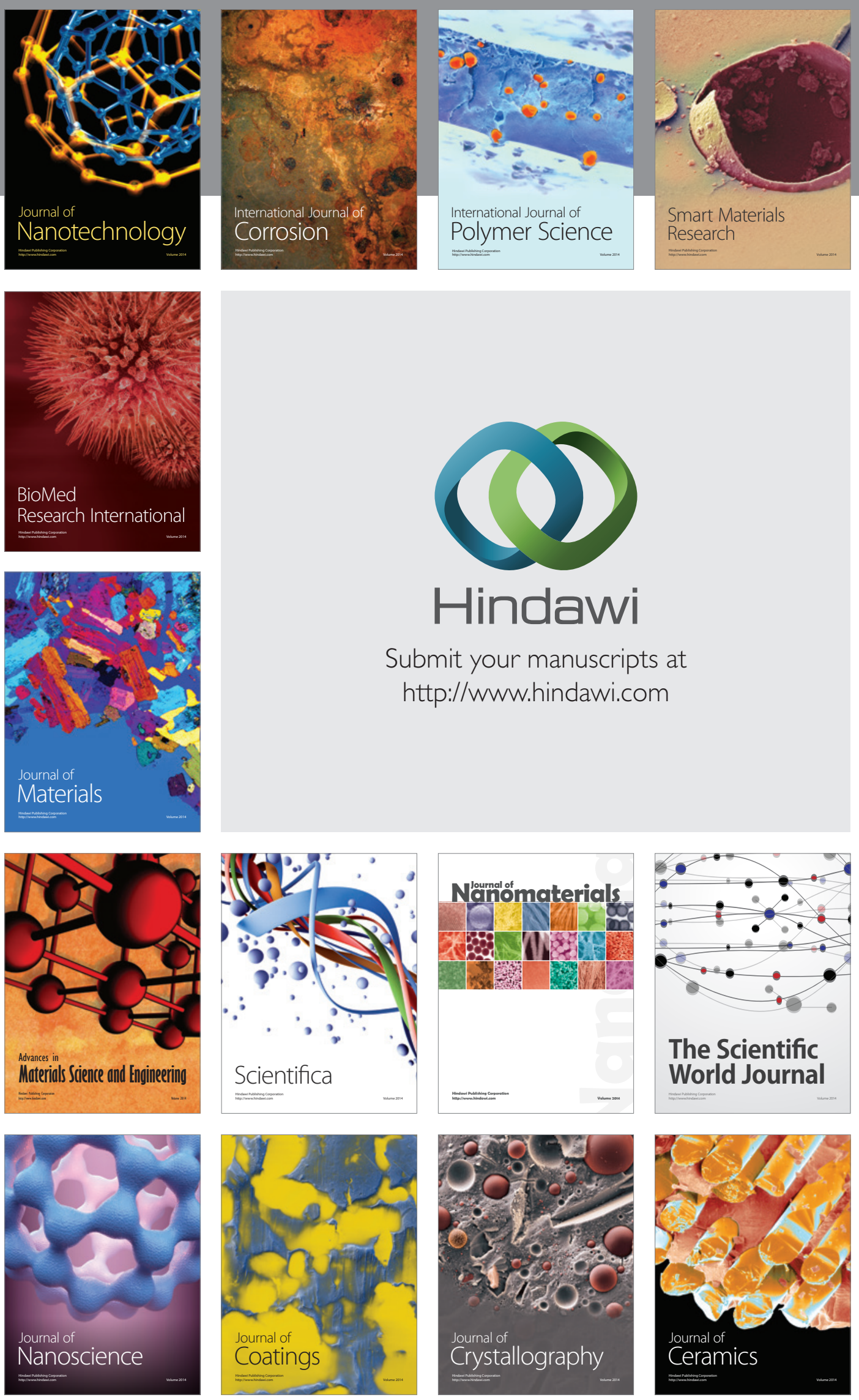

The Scientific World Journal

Submit your manuscripts at

http://www.hindawi.com

\section{World Journal}

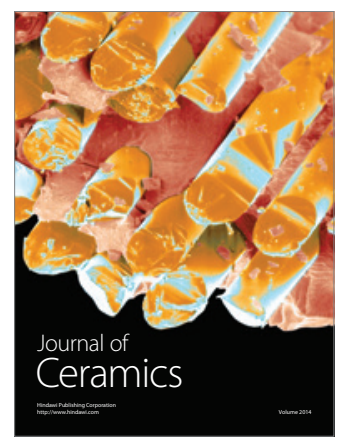

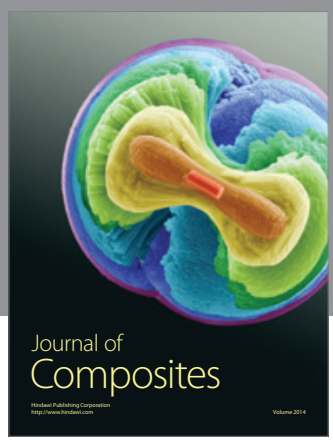
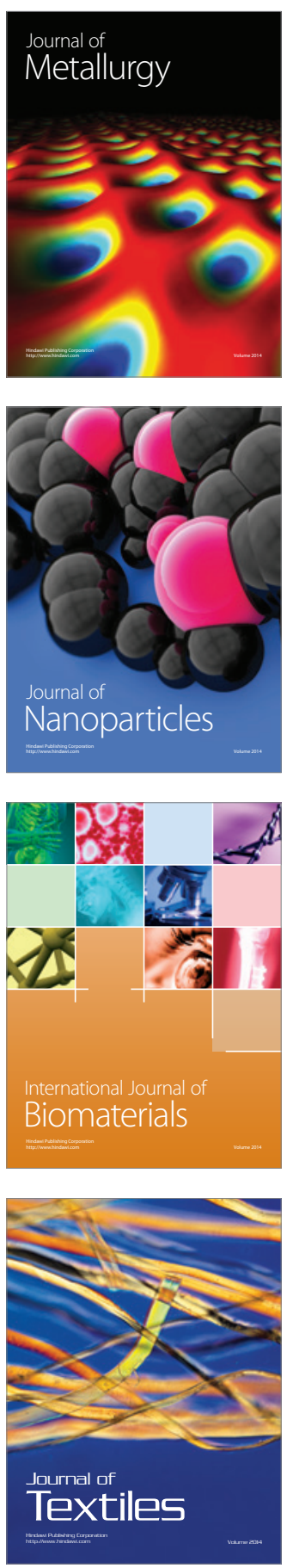